\title{
Assessing the impact of population, income and technology on energy consumption and industrial pollutant emissions in China
}

\author{
Yansui Liu ${ }^{\mathrm{a}, \mathrm{b}, \mathrm{c}}$, Yang Zhou ${ }^{\mathrm{b}, \mathrm{c}, *}$, Wenxiang $\mathrm{Wu}^{\mathrm{b}}$ \\ ${ }^{a}$ College of Resources Science and Technology, Beijing Normal University, Beijing 100875, China \\ ${ }^{\mathrm{b}}$ Institute of Geographic Sciences and Natural Resources Research, Chinese Academy of Sciences, Beijing 100101, China \\ ${ }^{\mathrm{c}}$ Key Laboratory of Regional Sustainable Development Modeling, Chinese Academy of Sciences, Beijing 100101, China
}

\section{H I G H L I G H T S}

- We assessed human impact on energy use and three types of industrial pollutant emissions in China.

- Higher population density would decrease energy use and pollutant emissions.

- The impact of economic development on the environment varies across regions.

- Higher industrial energy intensity would lead to higher levels of emissions.

- We did not find evidence of the EKC hypothesis for industrial waste in China.

\section{A R T I C L E I N F O}

\section{Article history:}

Received 4 December 2014

Received in revised form 8 June 2015

Accepted 17 June 2015

Available online 13 July 2015

\section{Keywords:}

Population density

Energy consumption

Industrial pollutant emissions

STIRPAT model

EKC hypothesis

China

\begin{abstract}
A B S T R A C T
Elucidating the complex mechanism of the impact of demographic changes, economic growth, and technological advance impacts on energy consumption and pollutant emissions is fundamentally necessary to inform effective strategies on energy saving and emission reduction in China. Here, based on a balanced provincial panel dataset in China over the period 1990-2012, we used an extended STIRPAT model to investigate the effects of human activity on energy consumption and three types of industrial pollutant emissions (exhaust gases, waste water and solid waste) at the national and regional levels and tested the environmental Kuznets curve (EKC) hypothesis. Empirical results show that a higher population density would result in a decrease in energy consumption in China as a whole and in its eastern, central and western regions, but the extent of its effect on the environment depends on the type of pollutants. Higher population density increased wastewater discharge but decreased solid waste production in China and its three regions. The effect of economic development on the environment was heterogeneous across the regions. The proportion of industrial output had a significant and positive influence on energy consumption and pollutant emissions in China and its three regions. Higher industrial energy intensity resulted in higher levels of pollutant emissions. No strong evidence supporting the EKC hypothesis for the three industrial wastes in China was found. Our findings further demonstrated that the impact of population, income and technology on the environment varies at different levels of development. Because of the regional disparities in anthropogenic impact on the environment, formulating specific region-oriented energy saving and emission reduction strategies may provide a more practical and effective approach to achieving sustainable development in China.
\end{abstract}

(c) 2015 Elsevier Ltd. All rights reserved.

\section{Introduction}

Over the past three decades, China has been experiencing a rapid economic growth with accelerating industrialisation and

\footnotetext{
* Corresponding author at: Institute of Geographic Sciences and Natural Resources Research, Chinese Academy of Sciences, 11A Datun Road, Chaoyang District, Beijing 100101, China. Tel.: +86 1064889034

E-mail address: zhouyang@igsnrr.ac.cn (Y. Zhou).
}

urbanisation. The sustained economic growth was largely achieved at the cost of over-consumption of energy resources, which inevitably caused many environmental problems that included air and water pollution, waste disposal, and massive energy demand [1-5]. According to the 2014 Environmental Performance Index (EPI) released by Yale University and Columbia University, China's environmental performance was relatively poor, ranking the 118th out of 178 countries [6]. Several factors have been recognised as the driving forces of such poor environmental 
performance; industrialisation is one primary force. China's State Environmental Protection Administration estimated that industrial pollution accounts for over $70 \%$ of the nation's total pollution emissions [7]. Industrial exhaust (or flue) gases, ${ }^{1}$ wastewater and solid waste have been long regarded to be the primary issues affecting environmental quality and sustainable development in China $[1,8]$. The First National Census of Pollution Sources in China, conducted in 2007, showed that the country's total amount of industrial exhaust gas emissions was 6122 million cubic metres $\left(\mathrm{m}^{3}\right)$, and the amount of solid waste production and wastewater discharge reached 3.85 and 24 billion tons, respectively [9]. Exacerbating such problems is the fact that many polluting industries are located in densely populated areas, where increased emissions exposure poses a serious threat to human health. The World Bank estimated that the health and non-health cost of air and water pollution in China was approximately 100 billion USD per year [10]. In the process of rapid industrialisation, water pollution has exacerbated the severe water scarcity problems in China. Faced with such increasing challenges, the Chinese government set binding targets in the "Twelfth Five-Year Plan" to reduce the unit GDP energy consumption by $16 \%$ and the total discharge of $\mathrm{CO}_{2}, \mathrm{SO}_{2}, \mathrm{NO}_{\mathrm{x}}$ and $\mathrm{COD}$ by $17 \%, 8 \%$, $8 \%$ and $10 \%$ by the end of 2015 (compared with the 2010 levels), respectively.

Rapid urbanisation has occurred along with the accelerating industrialisation. As the most populous country in the world, China has experienced unprecedented urbanisation since economic reforms initiated in 1978. The level of urbanisation in China has increased from $19.4 \%$ in 1980 to $54.4 \%$ in 2014 and is predicted to reach $61 \%$ and $75.8 \%$ by 2030 and 2050, respectively [11]. Urbanisation will most likely continue to be one of the main driving forces for China's economic development. As a result, more urban infrastructure will inevitably be required to support the continuously growing urban population, which will potentially lead to greater energy demand, in turn exerting additional pressure on fragile ecosystems [12]. Therefore, researches concerning specific factors that have an impact on energy consumption and pollutant emissions and the extent of their impact have been of great importance because these factors directly influence the formulation of pollutant abatement measures, policies and strategies in China [13].

The complex nexus between human activities and environmental impact has been extensively studied with various methods and results over the past decades. The representative models include the input-out model [14], the IPAT or STIRPAT model [15], the LMDI method [16] and so forth. Among them, the STIRPAT (stochastic impact by regression on population, affluence and technology) model is a well-known method that is widely used to examine the impact factors of energy use or pollutant emissions because the model can be expanded to incorporate additional factors. Demographic changes, economic growth and technological advances are usually acknowledged to be the key factors influencing energy consumption and pollutant emissions, and their impact on pollutant emissions are demonstrated to be heterogeneous across different countries and regions [12,13,17-21]. However, the question as to relationship between different levels of development, technology and population and environmental impact in each country remains to be resolved. Furthermore, the EKC hypothesis has also been introduced into the STIRPAT model in recent years to determine whether there is an inverted U-shaped relationship between per capita income and pollutant emissions

\footnotetext{
${ }^{1}$ In this study, industrial exhaust gases refer to the pollutant-containing gas emitted into atmosphere in the fuel combustion and production processes mainly as result from industrial process, while the exhaust gases emitted by automobiles are not include and discussed in this study. The "industrial exhaust gases" include a combination of sulphur dioxide, nitrogen oxides, and soot and dust.
}

[15,22-24]. The mixed results concerning the validation of EKC hypotheses for environmental quality in China have also been obtained. Some studies have found evidence supporting the existence of an EKC for pollutant emissions [22,25,26], whereas inconsistent findings have also been detected [27-29]. Therefore, further validation of the EKC hypothesis in China is imperative. Moreover, regional discrepancies in geographical and biophysical conditions exist in China, and the related environmental issues affected by anthropogenic activities vary across regions as well. Further investigation of the relationship between demographic changes, economic development, technological advances and pollutant emissions in China with consideration of regional differences is also necessary. Thus, the main aim of this study was to examine the impacts of population, income and technology on energy consumption and industrial pollutant emissions in China by national and regional analyses. Specifically, based on a balanced panel dataset of 30 provinces in China over the period 1990-2012, we used an extended STIRPAT model to investigate the factors influencing energy consumption and industrial pollutant emissions accounting for the regional differences, to assess the extent of their impacts on energy consumption and emissions, and to test the EKC hypothesis. These research results would provide theoretical guidance for formulating effective strategies on energy conservation and emission reduction in China.

The remainder of this paper is organized as follows: Section 2 describes the literature review; Section 3 introduces theoretical base and methodology; Section 4 presents the data; Section 5 describes and discusses the main results; and Section 6 offers conclusions and policy implications.

\section{Literature review}

Past studies on the effects of anthropogenic activities on the environment can be roughly divided into two lines of research. The first strand primarily focuses on the relationships between demographic changes, energy consumption and pollutant emissions at different scales with various methods and results. Among these human factors, demographic changes, including changes in population size, urbanisation, and the size and age composition of households, have implications for the patterns of energy consumption and pollutant emissions $[18,21]$. The elasticity of population size to $\mathrm{CO}_{2}$ emissions depended on the type of data and the research methods used [18]. Studies using time-variant data have produced much greater variance in population elasticity estimations [12,28,30,31]; whereas cross-sectional analyses typically have estimated population elasticity near one [15].

The relationships between urbanisation, energy consumption and $\mathrm{CO}_{2}$ emissions have been studied extensively in recent decades but have generated inconsistent results. Some studies have shown that urbanisation increases energy consumption and produces a higher level of emissions [12,15,31-33]. Using the STIRPAT model, Cole and Neumayer [31] found that urbanisation increases $\mathrm{CO}_{2}$ emissions. Poumanyvong and Kaneko [12] concluded that urbanisation decreases energy consumption in low-income countries but increases energy use in middle- and high-income countries, and the impact of urbanisation on emissions is positive. Zhang and Lin [32] and Wang et al. [34] also found that urbanisation increases energy consumption and $\mathrm{CO}_{2}$ emissions in China. Some researchers also identified urbanisation as one of the primary driving forces for the increase in $\mathrm{CO}_{2}$ emissions in Beijing [28] and Guangdong province [35]. Similar evidence was also obtained in OECD countries [36,37] and European Union countries [38]. Conversely, others argued that urbanisation improves the efficient use of public infrastructures and thus lowers energy use and emissions $[17,39]$. Studies have indicated that urbanisation had a negative impact on per capita road energy use in OECD countries but 
the impact on aggregate carbon emissions was not significant $[17,19]$. Sharma [40] also revealed that economic growth and energy consumption increase emissions but the urbanisation decreases emissions at the global level. Ponce and Marshall [41] argued that the relationship between urbanisation and $\mathrm{CO}_{2}$ emissions depends on income level and environmental policy, and that urbanisation decreased emissions for countries with stronger environmental policies and outcomes. Although most existing studies have claimed that urbanisation is positively correlated with energy consumption and carbon emissions, Liddle [18] argued that the correlation is a function of income's/development's positive association with both urbanisation and energy/emissions. Population density has considerable explanatory power compared to income in energy/emission studies [17-19]. Thus, Liddle [18] suggested that the regional population-environment studies should be focused on population density rather than urbanisation.

Among the demographic factors, the impact of age structure and household size on energy consumption and $\mathrm{CO}_{2}$ emissions has also attracted widespread concerns in recent years. Using the STIRPAT model, Fan et al. [13] found that the working-age population (aged 15-64 years) had a negative impact on $\mathrm{CO}_{2}$ emissions in developed countries, but had a positive impact in developing countries. Liddle and Lung [19] identified a positive elasticity for young adults (aged 20-34 years) and a negative elasticity for older adults (aged 35-64 years). Furthermore, Liddle [18] found that household size was negatively related to road energy use in OECD countries. Cole and Neumayer [31] also revealed a negative correlation between household size and carbon emissions in both developed and developing countries.

The second strand of research largely examines the relationship between economic growth and pollutant emissions with a particular focus on validation of the EKC hypothesis. Selden and Song [42] revealed an inverted U-shaped linkage between four air pollutant emissions (suspended particulate matter, $\mathrm{SO}_{2}, \mathrm{NO}_{\mathrm{x}}$, and $\mathrm{CO}_{2}$ ) and economic growth. Roca et al. [43] studied the relationships between income and six atmospheric pollutants $\left(\mathrm{CO}_{2}, \mathrm{SO}_{2}, \mathrm{~N}_{2} \mathrm{O}\right.$, $\mathrm{CH}_{4}, \mathrm{NO}_{\mathrm{x}}$, and no mechanical volatile organic compounds) in Spain and found evidence to support the EKC hypothesis, except in the case of $\mathrm{SO}_{2}$. Fodha and Zaghdoud [44] observed an inverted $\mathrm{U}$-shaped curve for $\mathrm{SO}_{2}$ emissions in Tunisia. Martinez-Zarzoso and Maruotti [45] revealed an inverted U-shaped nonlinear relationship between urbanisation and $\mathrm{CO}_{2}$ emissions in developing countries. Similar evidence was also obtained from OECD countries [46], Romania [47] and Tunisia [48]. However, inconsistent conclusions were also drawn from some recent studies. For example, Park and Lee [49] studied the relationship between economic development and air pollution ( $\mathrm{NO}, \mathrm{SO}_{2}$ and $\mathrm{NO}_{2}$ ) at the regional level in Korea and argued that the shape of the EKC depended on the type of pollutants. Zhu et al. [33] also concluded that an inverted U-shaped relationship between urbanisation and $\mathrm{CO}_{2}$ emissions in 20 emerging countries was not supported. With accelerated urbanisation and the growing environmental stress, research related to the issues in China received widespread attention in recent decades. Shen [25] reported an inverted U-shaped relationship for COD, arsenic and cadmium emissions, whereas no remarkable linkages were found for dust fall in China. Song et al. [26] showed an inverted U-shaped linkage for the relationship between economic growth and three types of pollutant emissions (exhaust gases, wastewater, and solid waste). Jalil and Mahumd [22] confirmed the existence of the EKC hypothesis for $\mathrm{CO}_{2}$ emissions in China. By contrast, Wang et al. [27] observed a U-shaped relation between economic growth and $\mathrm{CO}_{2}$ emissions in China. Other studies have also found no strong evidence to support the EKC hypothesis for $\mathrm{CO}_{2}$ emissions in China or Beijing [28,29].

These studies provide a scientific basis for effective energy saving and emission reduction strategies for different countries and regions. However, most existing studies have mainly focused on the relationships between urbanisation, energy use and $\mathrm{CO}_{2}$ emissions from a national perspective without much consideration for regional disparities, which may lead to a lack of understanding of the anthropogenic impacts on the environment across regions. Although a few recent studies examined the effects of urbanisation on $\mathrm{CO}_{2}$ emissions and considered regional differences [12,32,45], little empirical work has focused on industrial pollutants, particularly on the regional scale in China. China's environmental problems induced by industrial pollutant emissions are extremely serious. Thus, it is urgent that the relationships among demographic changes, economic growth, energy consumption and industrial pollutant emissions are fully investigated to provide the necessary information for policymakers and urban planners in China.

\section{Theoretical background and methodology}

\subsection{Theoretical base}

Fig. 1 shows the relationship between human activities and environmental impact. With accelerating urbanisation and industrialisation, rapid population growth and economic development may consume more energy and emit more pollutants, exerting pressure on the environment. However, the impact of human activities on the environment may be mitigated when the level of economic development reaches a certain threshold.

The effect of demographic, economic and technological factors on the environment is mainly postulated in the IPAT model ( $\mathrm{I}=\mathrm{PAT}$ ), which is firstly proposed by Ehrlich and Holdren [50]. The IPAT equation specifies the anthropogenic environmental impact $(I)$ as a function of population $(P)$, affluence ( $A$, usually proxied by per capita GDP) and technology ( $T$, generally identified as the impact of per unit of economic activity).

The IPAT model is limited because it analyzes a problem by changing a factor while keeping others constant, resulting in proportionate impacts on the dependent variable [20,51]. To overcome these weaknesses, Dietz and Rosa [51] reformulated the IPAT model into a stochastic model (STIRPAT), which can statistically assess non-monotonic or non-proportional impacts of driving forces on the environment. York et al. [15] refined the STIRPAT model and expanded it by incorporating additional factors, such as quadratic terms or different components of $P, A$ or $T$. The STIRPAT model has been successfully utilized to analyze the effects of driving forces on various environmental impact [12,15,28,35]. The STIRPAT model can be given as following equation:

$I_{i t}=\alpha P_{i t}^{\mathrm{b}} A_{i t}^{\mathrm{c}} T_{i t}^{d} \varepsilon_{i t}$

After taking logarithms, the model takes the following form:

$\operatorname{Ln}\left(I_{i t}\right)=a+b \operatorname{Ln}\left(P_{i t}\right)+c \operatorname{Ln}\left(A_{i t}\right)+d \operatorname{Ln}\left(T_{i t}\right)+\varepsilon_{i t}$

here, suffixes $i$ and $t$ refer to provinces and years, respectively; $P$ is population size; $A$ is real GDP per capita; $T$ is technology; and the dependent variable $I$ stands for pollutant emissions; $\varepsilon_{i}$ is the error term, $a$ is the constant term; $b, c$ and $d$ are, respectively, the coefficients of $P, A$ and $T$.

\subsection{Improved STIRPAT model}

The STIRPAT model allows other factors to be included to explore their effects on environmental parameters. In the STIRPAT model, factors $P$ and $A$ are decomposable, as is $T$ [15]. To further examine the impact of population, income and technology on energy consumption and industrial pollutant emissions in China, population density, economic structures and industrial 


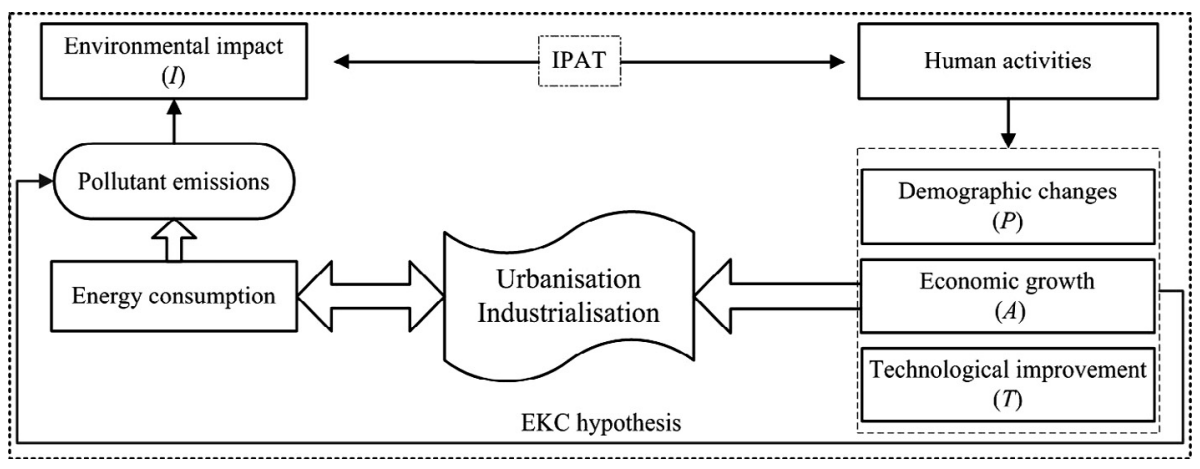

Fig. 1. Population, economy, technology and environment.

energy intensity were incorporated into an extended STIRPAT model. Liddle and his collaborators have demonstrated that population density was a better indicator than urbanisation in regional population-environment studies (the share of population living in urban areas) [17-19]. Thus, this study used population density as a proxy indicator of demographic changes. Following the study of York et al. [15], in this study, technology improvement was measured by three variables: the share of the added values of industry, tertiary industry in the real GDP, and industrial energy intensity. Additionally, York's method was used to establish the quadratic models for the affluence factor to verify whether the EKC hypothesis operated in China [15]. The improved STIRPAT model was changed as follows:

$$
\begin{aligned}
\operatorname{Ln}\left(\frac{E C_{i t}}{P_{i t}}\right)= & a_{0}+a_{1} \operatorname{Ln}\left(\mathrm{POPD}_{i t}\right)+a_{2} \operatorname{Ln}\left(\mathrm{pGDP}_{i t}\right)+a_{3} \operatorname{Ln}\left(\mathrm{INDU}_{i t}\right) \\
& +a_{4} \operatorname{Ln}\left(\mathrm{TERT}_{i t}\right)+\varepsilon_{1 i t}
\end{aligned}
$$

$$
\begin{aligned}
\operatorname{Ln}\left(\frac{I_{i t}}{P_{i t}}\right)= & b_{0}+b_{1} \operatorname{Ln}\left(\mathrm{POPD}_{i t}\right)+b_{2} \operatorname{Ln}\left(\mathrm{pGDP}_{i t}\right)+b_{3}\left[\operatorname{Ln}\left(\mathrm{pGDP}_{i t}\right)\right]^{2} \\
& +b_{4} \operatorname{Ln}\left(\operatorname{INDU}_{i t}\right)+b_{5} \operatorname{Ln}\left(\mathrm{TERT}_{i t}\right)+b_{6} \operatorname{Ln}\left(\operatorname{IEI}_{i t}\right)+\varepsilon_{2 i t}
\end{aligned}
$$

where $P$ is the total population and POPD is the population density; pGDP is the real per capita GDP; INDU and TERT are the shares of the added values of industry and tertiary industry in the GDP, respectively; IEI is the industry energy intensity (expressed as industry energy use per unit GDP); $E C$ is per capita energy consumption; and $I$ represents the environmental impact (with three types of industrial pollutant emissions per capita as proxies, i.e., exhaust gases, wastewater and solid waste). $\varepsilon_{i t}$ is the error term, $a_{0}$ and $b_{0}$ are the constant terms; and $a_{\mathrm{i}}$ and $b_{\mathrm{i}}$ are the estimated coefficients of the dependent variables. The industrial energy intensity is included in only the emission models because it contains part of the dependent variable.

The EKC theory states that environmental degradation initially increases with income during the early stages of economic growth and then decreases, with income arriving afterward at a turning threshold [52]. According to the EKC hypothesis, an inverted $\mathrm{U}$-shaped relationship between per capita income and pollutant emission exists if the coefficient $b_{2}$ is statistically significant and positive, while the coefficient $b_{3}$ is statistically significant and negative (i.e., $b_{2}>0$ and $b_{3}<0$ ) and the turning point of the EKC is computed by $\omega=\exp \left(-0.5 b_{2} / b_{3}\right)$. A U-shaped linkage exists between per capita emissions and income if the coefficient $b_{2}$ is statistically significant and negative and the coefficient $b_{3}$ is statistically significant and positive $\left(b_{2}<0\right.$ and $\left.b_{3}>0\right)[15,17,22-24,52]$.

\subsection{Model estimation}

Two steps were performed to examine the impact of population, income and technology on energy consumption and pollutant emissions for the entirety of China and for the three regions (i.e., eastern, central and western China, see Fig. A.1 in Appendix A). First, the presence of unit roots in all variables was verified before proceeding to any econometric analysis because using the conventional ordinary least squares (OLS) estimator with non-stationary variables may have resulted in spurious regressions. The Peraran (2007) CIPS test [53], as one of the second-generation panel unit root tests, was performed to test the stationarity of the all variables. The second-generation panel unit root test is valid for both unbalanced panels and panels in which the cross-sectional and time dimensions are of the same order of magnitude [24,53]. The results of that test suggested that many variables are non-stationary in their levels, but most of them become stationary at the 5\% significance level after taking first differences, which indicated that the variables in all panels are integrated of order one or $I(1)$ (see Table A.1 in Appendix A).

Second, the impact of human activities on energy use and pollutant emissions for the whole sample and for the three regions was estimated using three methods: fixed effects (FE), the feasible generalized least squares (FGLS) and the linear regression with Driscoll-Kraay standard errors (DK), generating forty-four models. Specifically, the FE estimation was used to alleviate heterogeneity bias. The autocorrelation in the fixed effect models was verified by the Wooldridge test and the autocorrelation in the fixed effect models was found [54]. Moreover, we confirmed the presence of groupwise heteroskedasticity in the all modes using the modified Wald statistic [55]. We also detected the existence of cross-sectional dependence by Pesaran test in the fixed effect models [56]. The FGLS estimation was employed to address those issues. However, the FGLS method is infeasible if the panel's time dimension $T$ is smaller than its cross-sectional dimension $N$, and it tends to produce unacceptably small standard error estimates [57]. To solve the issues, the Driscoll-Kraay estimation was applied. Besides being heteroscedasticity consistent, the Driscoll-Kraay standard error estimates are robust to general forms of cross-sectional and temporal dependence [32,58]. Because the DK estimation was robust to cross-sectional dependence, the emphasis was placed only on the estimation; the interpretations focused only on the results based on the DK models. The estimated results for FE and FGLS models were listed in Tables A.2 and A.3 in Appendix A. Additionally, the multicollinearity among the explanatory variables in the DK models was tested by the variance inflation factors (VIF). The VIF values are all less than 10, indicating no multicollinearity (see Table A.4 in Appendix A). 
Table 1

Description of the variables used in the study over the period 1990-2012.

\begin{tabular}{|c|c|c|}
\hline Variable & Definition & Unit of measurement \\
\hline Population density (POPD) & Ratio of a population to a given unit of area & Person per sq. km \\
\hline GDP per capita (pGDP) & GDP divided by population at the end of the year & Yuan per capita \\
\hline Proportion of industrial output (INDU) & Percentage of the added value of industrial sector in GDP & Percent \\
\hline $\begin{array}{l}\text { Proportion of tertiary industry output } \\
\quad \text { (TERT) }\end{array}$ & Percentage of the added value of tertiary industry in GDP & Percent \\
\hline Energy use per capita (EC) & Sum of energy consumption divided by total population at the end of the year & Tce per capita \\
\hline Industry energy intensity (IEI) & Total industry energy use divided by GDP & $\begin{array}{l}\text { Tce per ten thousand yuan } \\
\text { (RMB) }\end{array}$ \\
\hline Exhaust gas emissions per capita (FQ) & $\begin{array}{l}\text { Total volume of pollutant-containing gas emitted into the atmosphere divided by the total } \\
\text { population }\end{array}$ & Hundred million cubic metres \\
\hline Waste water discharge per capita (FS) & $\begin{array}{l}\text { Total volume of waste water discharge by industrial enterprises divided by the total } \\
\text { population }\end{array}$ & Ton per capita \\
\hline Solid waste production per capita (FW) & $\begin{array}{l}\text { Total volume of solid waste that is not regarded to be hazardous divided by the total } \\
\text { population }\end{array}$ & Ton per capita \\
\hline
\end{tabular}

\section{Data source and description}

\subsection{Data sources}

This study makes full use of a balanced panel dataset of 30 provinces in China over the period 1990-2012 (Hong Kong, Macao, Taiwan and Tibet are excluded for lack of data). The provincial data on three types of industrial pollutant emissions, i.e., exhaust gases (denoted by FQ), wastewater (FS) and solid waste (FW) are collected from the China Environmental Yearbook. The data of the provincial population size, GDP, population density, industrial output, added values of the industry and tertiary industry are derived from the China Statistical Yearbook and the China Compendium of Statistics. The data on total energy consumption are obtained from the China Energy Statistical Yearbook and Statistical Yearbook of the various provinces, municipalities and autonomous regions. To eliminate the influence of the price index, the GDP is calculated at a constant price (1990 prices) and the proportion of industry and tertiary industry output in GDP are calculated accordingly. Table 1 provides a detailed description of all variables used in this study.

\subsection{Data description}

Summary statistics and correlations, and cross-section independence (CD) tests among the variables are displayed in Table 2. Population density was negatively correlated with energy consumption and industry pollutant emissions except for wastewater, but the correlation was weak. The per capita GDP and the share of the added value of the industrial sector in GDP were positively correlated with energy consumption and pollutant emissions. The three types of industrial pollutant emissions were also positively associated with energy consumption but negatively correlated with industry energy intensity. In addition, the results of the $C D$ test clearly indicated the presence of cross-sectional dependence for all variables.

Simple linear regressions were used to examine the changes in population density, energy use and pollutant emissions for 30 provinces in China during the period 1990-2012. The slopes of the lines of best fit reflected the changes in the variables, and a greater slope indicated greater changes in the variables. Over the period 1990-2012, the growth rate of the population in eastern China was relatively higher than those in the central and western regions (Fig. 2a). The five provinces with the highest population growth rates were Shanghai, Beijing, Tianjin, Hainan and Guangdong. For energy consumption, the growth rate in Shandong province was the highest, followed by Guangdong and Jiangsu (Fig. 2b). These results showed that the rapid population growth in most provinces of eastern China was accompanied by a significant increase in energy consumption over the past two decades.
Table 2

Summary statistics and correlations (all variables in natural logarithms).

\begin{tabular}{lcclrrrlll}
\hline Variable & Obs & Mean & Std. Dev. & Min. & Max. & \multicolumn{2}{l}{ CD test } \\
\cline { 7 - 10 } & & & & & & & CD statistics & Abs (corr) \\
\hline EC & 690 & 0.43 & 0.66 & -1.68 & 2.07 & $94.69^{* * *}$ & 0.95 \\
FQ & 690 & 9.63 & 0.82 & 7.11 & 12.46 & $86.99^{* * *}$ & 0.89 \\
FS & 690 & 2.74 & 0.53 & 1.18 & 4.61 & $13.18^{* * *}$ & 0.52 \\
FW & 690 & -0.27 & 0.79 & -2.38 & 3.07 & $79.12^{* * *}$ & 0.87 \\
POPD & 690 & 5.38 & 1.27 & 1.83 & 8.32 & $84.25^{* * *}$ & 0.84 \\
pGDP & 690 & 8.48 & 0.81 & 6.69 & 10.47 & $99.11^{* * *}$ & 0.99 \\
INDU & 690 & 3.58 & 0.38 & 1.91 & 4.09 & $27.55^{* * *}$ & 0.48 \\
TERT & 690 & 3.59 & 0.18 & 3.02 & 4.34 & $63.21^{* * *}$ & 0.64 \\
IEI & 690 & 1.05 & 0.81 & -3.26 & 2.97 & $83.63^{* * *}$ & 0.84 \\
& EC & FQ & FS & FW & POPD & pGDP & INDU & TERT & IEI \\
\hline
\end{tabular}

Correlations

EC 1

FQ $\quad 0.93 \quad 1$

FS $\quad 0.15-$

$\begin{array}{llllllll} & \text { FW } & 0.71 & - & - & 1\end{array}$

$\begin{array}{llllll}\text { POPD } & -0.04 & -0.02 & 0.35 & -0.23 & 1\end{array}$

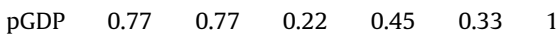

$\begin{array}{llllllll}\text { INDU } & 0.23 & 0.30 & 0.34 & 0.36 & 0.34 & 0.23 & 1\end{array}$

$\begin{array}{lllllllll}\text { TERT } & 0.49 & 0.39 & -0.06 & 0.13 & 0.15 & 0.57 & -0.34 & 1\end{array}$

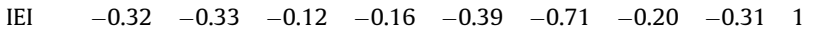

Notes: EC is energy consumption per capita; FQ, FS and FW are exhaust gas, wastewater and solid waste emissions per capita, respectively; POPD is population density; pGDP is real GDP per capita; IEI is industrial energy intensity; INDU and TERT are proportion of the industry and tertiary industry sectors, respectively. Obs is observations. CD is cross-section independence. Null hypothesis is cross-sectional independence. Abs(corr) is the absolute value correlation coefficient. The Pesaran (2004) CD test is performed using the Stata "xtcd" commend.

Implies statistical significance at the $1 \%$ level.

For industrial exhaust gas emissions, Hebei province had a significant increase of 291 billion $\mathrm{m}^{3}$ per year over the past 23 years, which was followed by the exhaust gas emissions from the provinces of Shandong, Jiangsu, Henan and Guangdong (Fig. 2c). The provinces with relatively rapid growth rates in generation of solid waste were Hebei, Henan, Shanxi, Inner Mongolia and Shandong (Fig. 2d). The rapid growth of solid waste production in these areas may be related to their abundant energy sources, especially coal and oil. For wastewater discharge, the trend increased in most provinces of eastern China, whereas both the central and western areas exhibited decreasing trends (Fig. 2e). The fast growth rate of industrial pollutant discharge in the eastern region may be attributed to its advanced industries and high population density. These results indicated that China's environmental management measures should consider the causes and the regional characteristics of environmental issues.

Table 3 lists population density, energy consumption and pollutant emissions per capita in eastern, central and western China in 


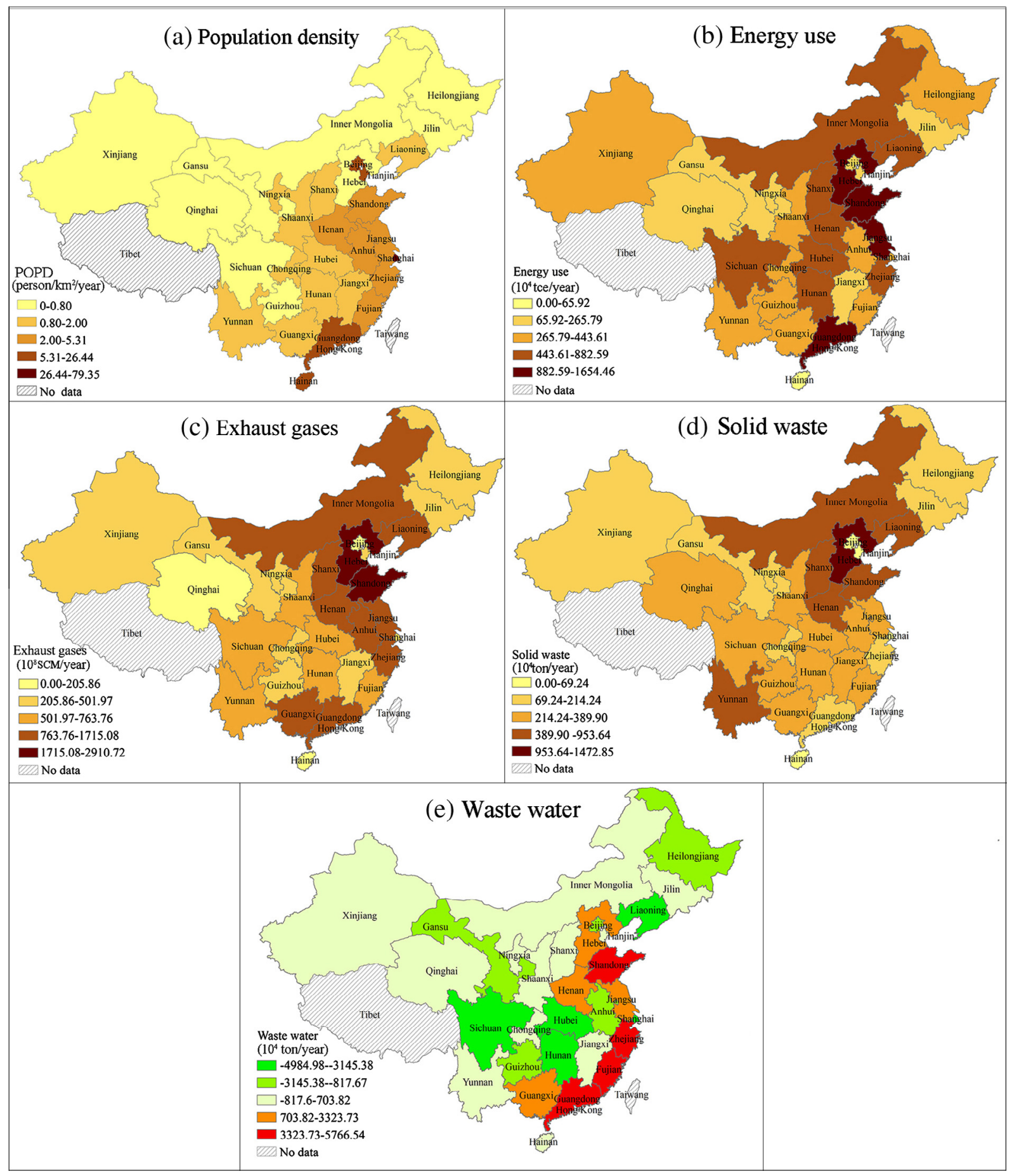

Fig. 2. Trend variations in (a) population density, (b) energy use, (c) exhaust gases, (d) solid waste and (e) wastewater discharge for 30 provinces in China between 1990 and 2012.

Table 3

Population density, per capita energy consumption and pollutant emissions for China's different regions in 1990 and 2012.

\begin{tabular}{|c|c|c|c|c|c|c|c|c|c|c|}
\hline \multirow[t]{2}{*}{ Region } & \multicolumn{2}{|l|}{ POPD } & \multicolumn{2}{|l|}{$\mathrm{EC}$} & \multicolumn{2}{|l|}{$\mathrm{FQ}$} & \multicolumn{2}{|l|}{ FS } & \multicolumn{2}{|l|}{ FW } \\
\hline & 1990 & 2012 & 1990 & 2012 & 1990 & 1990 & 1990 & 2012 & 1990 & 2012 \\
\hline Eastern & 636.68 & 981.66 & 1.26 & 3.83 & 11833.41 & 0.57 & 0.57 & 19.03 & 0.012 & 0.011 \\
\hline Central & 276.20 & 305.51 & 0.93 & 2.96 & 8244.80 & 0.62 & 0.62 & 14.53 & 0.017 & 0.013 \\
\hline
\end{tabular}

Notes: POPD is population density (persons per sq. $\mathrm{km}$ ); EC is per capita energy consumption (tces per person) and FQ, FS and FW are per capita exhaust gases (10 $0^{4} \mathrm{~m}^{3}$ per person), wastewater (tons per person) and solid waste (tons per person), respectively. 
1990 and 2012. Population density in the eastern region increased from 636.98 persons per square kilometre (sq. km) in 1990 to 981.66 persons per sq. $\mathrm{km}$ in 2012 . The density in the central region increased from 276.2 persons per sq. $\mathrm{km}$ in 1990 to 305.51 persons per sq. $\mathrm{km}$ in 2012, and the density in the western region increased from 120.97 persons per sq. $\mathrm{km}$ in 1990 to 133.04 persons per sq. $\mathrm{km}$ in 2012 . The growth rate of population density in eastern China (54.18\%) was faster than that in the western (10.61\%) and central (9.98\%) regions. By contrast, energy consumption per capita showed a different pattern. The increase in energy use per capita in the western region was greater than that in the other two regions and increased from 0.87 tons of coal equivalent (tce) in 1990 to 4.07 tce in 2012. The energy consumption per capita in the eastern region increased only by 2.58 tce, with an increase from 1.26 tce in 1990 to 3.83 tce in 2012, and in the central region, the increase was also slight from 0.93 tce in 1990 to 2.96 tce in 2012. This result may be related to the implementation of the China's Western Development policy in 2000.

The industrial pollutant emissions per capita in China also changed significantly over the past two decades. The per capita exhaust gas emissions in the western region showed a greater increase than that in the central and eastern areas and increased from $7258.4 \mathrm{~m}^{3}$ in 1990 to $64110.99 \mathrm{~m}^{3}$ in 2012. Similar to energy use, the increase in solid waste production per capita in the western region was larger than that in the central and eastern regions and increased from 0.49 tons in 1990 to 4.9 tons in 2012. For wastewater discharge, all three regions showed decreases; the decrease in discharge in the eastern area was greater than that in the other two regions.

\section{Empirical results and discussions}

\subsection{Human activities and energy consumption}

Based on the pooled OLS regression with Driscoll-Kraay standard errors $(\mathrm{DK}){ }^{2}$ the estimates of the impact of demographic changes, economic development and technology improvement on energy consumption for the whole sample and the eastern, central and western regions are shown in Table 4 . For the whole sample, all estimated coefficients were statistically significant at the level of $5 \%$ or lower. Additionally, the diagnostics are good: the residuals were stationary, and the cross-sectional dependence in the residuals cannot be rejected. The effect of GDP per capita and proportion of industrial and tertiary industry output on energy consumption were positive, whereas population density negatively affected energy use. The negative elasticity of population density to energy consumption in China was 0.211 , which indicates that a $1 \%$ increase in population density decreased energy use by $0.211 \%$. The elasticities of GDP per capita, proportion of industrial and tertiary industry output on energy use in China were $0.554,0.524$ and 0.968 , respectively. These results suggested that economic growth and changes in industrial structures contributed to the increase in energy consumption in China over the last two decades.

Similar to the national scale, all estimated coefficients of population, income and technology were statistically significantly and negatively correlated with energy consumption in the three regions at the $1 \%$ level. The negative effect of population density increase on energy consumption varied across regions, with the greatest impact in the central region, followed by the western and eastern areas (Fig. 3). Specifically, a $1 \%$ increase in population density decreased energy consumption by $0.239 \%, 0.218 \%$ and $0.065 \%$ in the central, western and eastern regions, respectively. This result was consistent with that by Liddle [17], who found that

\footnotetext{
2 The pooled OLS model is more preferable than the fixed-effects model and the test is not reported (similarly hereinafter), which are available on request.
}

a $1 \%$ increase in the level of population density decreased road energy use by $0.31-0.51 \%$ in OECD countries. Due to the lack of basic public services in many cities of the western region, the negative population density elasticity to energy use was likely the result of modernisation rather than of scale economies of public infrastructure [12]. Due to rapid economic growth and urbanisation, eastern China still required many private and public infrastructures to maintain their citizen's lives and economic activities, and more energy resources may be required to construct, maintain and operate the infrastructure. Therefore, the negative elasticity of population density to energy consumption in the eastern region was less than that in the central and western regions.

The influence of other factors on energy use was positive and differed across regions. The elasticity of the GDP per capita to energy use was 0.456 in the eastern region, slightly larger than the elasticity in the western (0.423) and central regions (0.279). The result indicated that economic development may have a strong and positive impact on energy consumption in the three regions, and the impact was the greatest in the eastern region, followed by the western and central regions. The findings by Wang et al. [28] and Poumanyvong and Kaneko [12] supported this result. The proportion of industrial output had a positive and significant effect on energy consumption in the three regions. A $1 \%$ increase in the proportion of industrial output increased energy consumption by $0.948 \%, 1.854 \%$ and $1.456 \%$ in the eastern, central and western regions, respectively. The effect of the proportion of tertiary industry on energy use was also positive and significant in the three regions at the level of $5 \%$ or lower. As the eastern region was the first involving in the Reform and Open in China, this region acquired abundant capital due to strong government support and a good socio-economic base. Rapid economic growth, urbanisation and industrialisation thus increased energy consumption in eastern China. Both the central and western regions have abundant energy resources, especially coal. Coupled with the influence of the Central Rise Strategy and the Western Development Strategy, the economic growth and industrialisation of the two regions has accelerated since 2005 and 2000, respectively, contributing to the increase of energy use [59].

\subsection{Human activities and industrial pollutant emissions}

\subsubsection{Industrial exhaust gases}

Table 5 provides the estimates of the impact of human activities on industrial exhaust gas emissions for the country and for the eastern, central and western regions. For the whole of China, exhaust gas emissions were statistically significantly and positively associated with the proportion of industrial output and energy intensity, whereas emissions were negatively correlated with population density at the $1 \%$ level. A $1 \%$ increase in population density decreased exhaust gas emissions by $0.209 \%$ in China. When other variables were kept constant, a $1 \%$ increase in energy intensity and the proportion of industrial output increased exhaust gas emissions by $0.341 \%$ and $0.558 \%$, respectively. Moreover, the impact of income per capita and proportion of tertiary industrial output on exhaust gas emissions in China were insignificant even at the $10 \%$ level.

At the regional scale, the increase in population density had a negative effect on exhaust gas emissions in the eastern region, whereas the impact in the central and western regions was insignificant. A $1 \%$ increase in population density decreased emissions by $0.094 \%$ in the eastern region (Fig. 4 ). Similar to the whole of China, the proportion of industrial output and energy intensity positively influenced exhaust gas emissions in the three regions. When the industrial energy intensity increased by $1 \%$, exhaust gas emissions increased by $0.643 \%, 0.136 \%$ and $0.617 \%$ in the eastern, central and western regions, respectively. The results indicated 
Table 4

Estimation results for per capita energy use by DK models, $95 \%$ confidence intervals in brackets. ${ }^{a}$

\begin{tabular}{|c|c|c|c|c|}
\hline Variable & Whole of China & Eastern region & Central region & Western region \\
\hline $\operatorname{Ln}(\mathrm{POPD})$ & $-0.211^{* * *}[-0.23 \quad-0.20]$ & $-0.065^{* * *}[-0.11 \quad-0.02]$ & $-0.239^{* * *}[-0.30 \quad-0.18]$ & $-0.218^{* * * *}[-0.24 \quad-0.20]$ \\
\hline $\operatorname{Ln}(\mathrm{pGDP})$ & $0.554^{* * * *}[0.51 \quad 0.60]$ & $0.456^{* * *}[0.34 \quad 0.58]$ & $0.279^{* * * *}[0.16 \quad 0.40]$ & $0.423^{* * *}[0.27 \quad 0.58]$ \\
\hline $\operatorname{Ln}(\mathrm{INDU})$ & $0.524^{* * * *}[0.46 \quad 0.59]$ & $0.948^{* * * *}[0.651 .25]$ & $1.854^{* * * *}\left[\begin{array}{ll}1.47 & 2.24\end{array}\right]$ & $1.456^{* * * *}\left[\begin{array}{ll}0.70 & 2.22\end{array}\right]$ \\
\hline $\operatorname{Ln}(\mathrm{TERT})$ & $0.968^{* * *}[0.751 .19]$ & $1.477^{* * *}[0.961 .99]$ & $1.160^{* * *}[0.501 .82]$ & $0.838^{* *}[0.061 .62]$ \\
\hline Constant & $-8.449^{* * *}[-9.30 \quad-7.69]$ & $-11.987^{* * * *}[-13.85-10.13]$ & $-11.614^{* * * *}[-14.79 \quad-8.43]$ & $-10.30^{* * * *}[-13.99-6.61]$ \\
\hline CIPS & $I(0)$ & $I(0)$ & $I(0)$ & $I(0)$ \\
\hline Mean rho & 0.18 & 0.15 & 0.21 & 0.31 \\
\hline $\mathrm{CD}(p)$ & $18.65(0.12)$ & $6.38(0.34)$ & $8.97(0.18)$ & $5.79(0.09)$ \\
\hline$R^{2}$ & 0.735 & 0.802 & 0.821 & 0.776 \\
\hline Obs & 690 & 253 & 184 & 184 \\
\hline
\end{tabular}

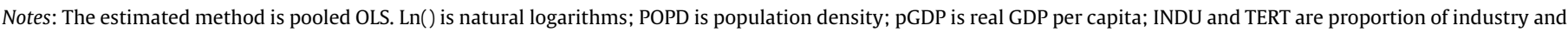

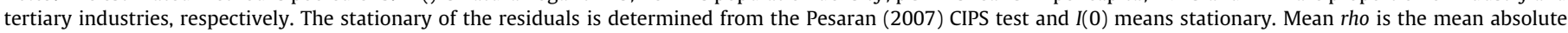

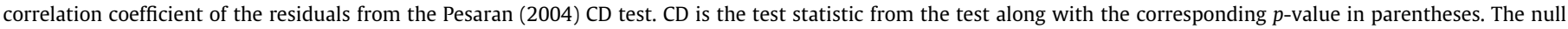
hypothesis is cross-sectional independence. Obs is observations.

${ }_{* * *}$ Indicate statistical significance at the $5 \%$ level.

*** Indicate statistical significance at the $1 \%$ level.

a The estimated results based on the FE and FGLS for energy consumption and pollutant emissions models are showed in Tables A.2-A.4 in the Appendix A.

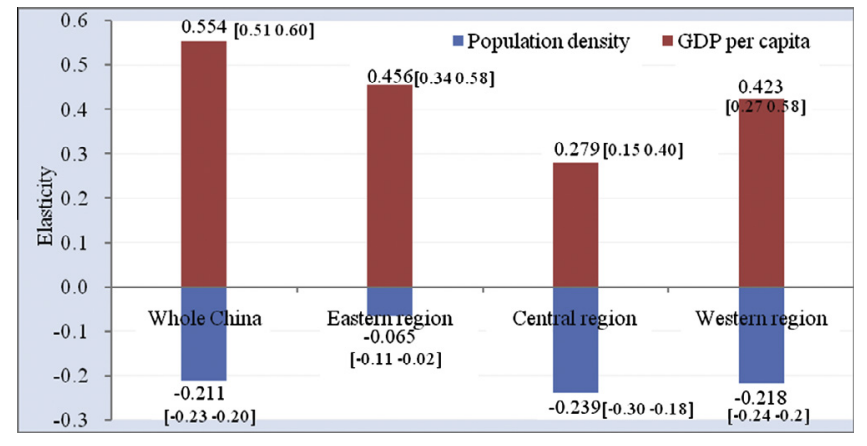

Fig. 3. Elasticity of population density and incomes per capita to energy consumption for the whole sample and the three regions (95\% confidence intervals in brackets).

that the impacts of industrial energy intensity on exhaust gas emissions in eastern and western China were greater than that at the central region. The elasticity of exhaust gas emissions to the proportion of industrial output were $0.885,2.063$ and 0.439 in the eastern, central and western regions, respectively. Furthermore, with a quadratic EKC specification, the estimated coefficients on income per capita and its squared value in both the central and western regions were significant with a negative and positive sign, respectively. This could point to the existence of a U-shaped relationship between per capita incomes and exhaust gas emissions in central and western China. However, the impact of economic development on exhaust gas emissions in the eastern region was not statistically significant at the $10 \%$ level or higher.

\subsubsection{Industrial wastewater}

Table 6 presents the estimates of the effects of population, income and technology on wastewater discharge for the country and the three regions. For the whole of China, the estimated coefficients were all statistically significant at the $1 \%$ level, except for the coefficient for income per capita and its squared term. The elasticity of industrial wastewater discharge to population density, industrial output and energy intensity in China were $0.127,0.188$ and 0.142 , respectively. This indicated that a $1 \%$ increase in population density increased wastewater discharge by $0.127 \%$ in China (Fig. 4). The proportion of tertiary industry output had a negative effect on industrial wastewater discharge in China, and a $1 \%$ increase in tertiary industry output resulted in a $0.58 \%$ decrease in the wastewater discharge.

At the regional level, population density also positively influenced wastewater discharge. The elasticity of population density to wastewater discharge in eastern, central and western China were $0.209,0.134$ and 0.132 , respectively, and a $1 \%$ increase in population density resulted in a $0.13-0.21 \%$ increase in wastewater

Table 5

Estimation results for per capita industrial exhaust gas emission by DK models, 95\% confidence intervals in brackets.

\begin{tabular}{|c|c|c|c|c|}
\hline Variable & Whole of China & Eastern region & Central region & Western region \\
\hline $\operatorname{Ln}(\mathrm{POPD})$ & $-0.209^{* * * *}[-0.24 \quad-0.18]$ & $-0.094^{* * *}[-0.15 \quad-0.04]$ & $-0.030[-0.19 \quad 0.13]$ & $-0.035[-0.09 \quad 0.02]$ \\
\hline $\operatorname{Ln}(\mathrm{pGDP})$ & $0.041[-1.83 \quad 1.92]$ & $-0.698[-3.19 \quad 1.79]$ & $-3.326^{* * *}[-5.03 \quad-1.62]$ & $-2.373^{* *}\left[\begin{array}{ll}-4.70 & -0.05\end{array}\right]$ \\
\hline $\operatorname{Ln}(\mathrm{pGDP})^{2}$ & $0.058[-0.05 \quad 0.17]$ & $0.105\left[\begin{array}{ll}-0.03 & 0.24\end{array}\right]$ & $0.235^{* * * *}[0.14 \quad 0.33]$ & $0.223^{* * * *}[0.090 .36]$ \\
\hline $\operatorname{Ln}($ INDU) & $0.558^{* * * *}[0.44 \quad 0.67]$ & $0.855^{* * * *}[0.601 .11]$ & $2.063^{* * * *}\left[\begin{array}{ll}1.27 & 2.86\end{array}\right]$ & $0.439^{* * * *}\left[\begin{array}{ll}0.02 & 0.90\end{array}\right]$ \\
\hline $\operatorname{Ln}(\mathrm{TERT})$ & $0.191\left[\begin{array}{ll}-0.09 & 0.47\end{array}\right]$ & $0.271[-0.12 \quad 0.67]$ & $1.284[0.71 \quad 1.86]$ & $0.257\left[\begin{array}{ll}-0.57 & 1.08\end{array}\right]$ \\
\hline $\operatorname{Ln}(\mathrm{IEI})$ & $0.341^{* * * *}[0.21 \quad 0.47]$ & $0.643^{* * * *}[0.29 \quad 1.00]$ & $0.136^{* * *}[0.02 \quad 0.25]$ & $0.617^{* * * *}[0.41 \quad 0.83]$ \\
\hline Constant & $3.117\left[\begin{array}{ll}-5.03 & 11.27\end{array}\right]$ & $3.527[-7.1914 .25]$ & $8.622^{* *}[0.4916 .75]$ & $10.826^{* * *}[0.38$ \\
\hline CIPS & $I(0)$ & $I(0)$ & $I(0)$ & $I(0)$ \\
\hline Mean rho & 0.16 & 0.15 & 0.19 & 0.24 \\
\hline $\mathrm{CD}(p)$ & $19.86(0.11)$ & $5.92(0.21)$ & $4.91(0.18)$ & $4.53(0.07)$ \\
\hline$R^{2}$ & 0.787 & 0.839 & 0.839 & 0.840 \\
\hline Obs & 690 & 253 & 184 & 184 \\
\hline
\end{tabular}

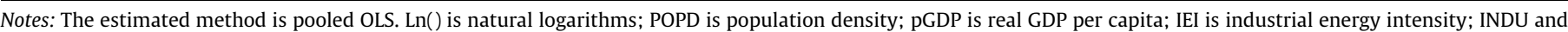

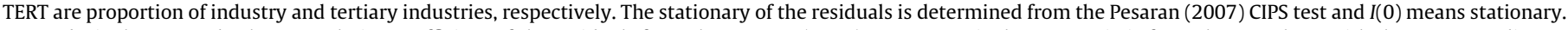

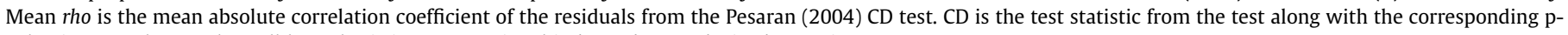
value in parentheses. The null hypothesis is cross-sectional independence. Obs is observations.

** Indicate statistical significance at the $5 \%$ level.

*** Indicate statistical significance at the $1 \%$ level. 


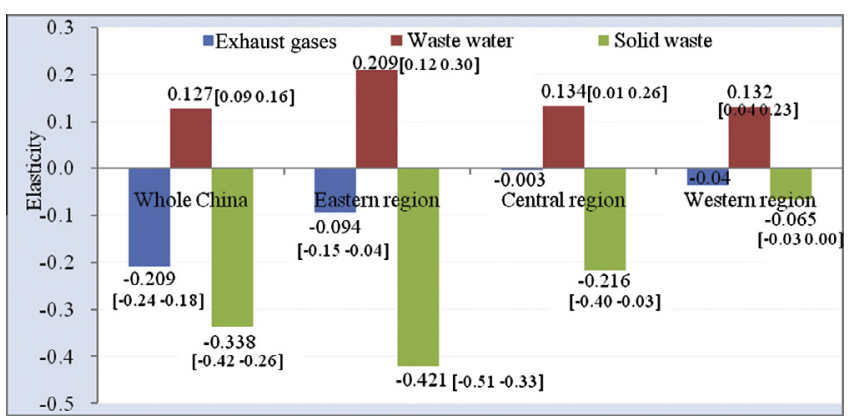

Fig. 4. Elasticity of population density to industrial pollutant emissions (exhaust gases, wastewater and solid waste) for the whole sample and the three regions (95\% confidence intervals in brackets) (The estimated elasticity of exhaust gases to population density in the central and western regions was listed but it is statistically insignificant at the level $10 \%$ or higher.).

discharge. The effect of energy intensity and economic structure on wastewater discharge was also heterogeneous across regions. The proportion of industrial output was positively correlated with the wastewater discharge in the eastern region, but correlations in the central and western regions were not significant. The significant positive correlation between energy intensity and wastewater discharge was detected only in the western region. Furthermore, the coefficients of income per capita and its squared term to wastewater discharge in the central region were statistically significant at the level of $10 \%$ with a negative and positive sign, respectively, indicating a U-shaped relationship. However, the correlations between per capita incomes and wastewater discharge in eastern and western China were statistically insignificant at the $10 \%$ level or higher.

\subsubsection{Industrial solid waste}

Table 7 lists the estimates of the impact of population and other variables on industrial solid waste production for whole China and its three regions. For the whole of China, energy intensity and the proportion of industrial output positively influenced industrial solid waste production, whereas population density negatively affected industrial solid waste production. A $1 \%$ increase in population density decreased industrial solid waste production by $0.338 \%$. The elasticities of industrial solid waste production to energy intensity and the proportion of industrial output were 0.971 and 0.151 , respectively. This indicated that energy intensity had a strong and positive influence on solid waste production in China. The elasticity of solid waste production to the proportion of tertiary industry output was positive but statistically not significant. Furthermore, the correlation between economic growth and solid waste production was also not significant at the $10 \%$ level or higher.

The estimated coefficients were all statistically significant at the $5 \%$ level or lower for the three regions. Higher population density had a negative influence on solid waste production at the regional level. With a $1 \%$ increase in population density, solid waste production in the eastern, central and western regions decreased by $0.421 \%, 0.216 \%$ and $0.065 \%$, respectively. This result was supported by Liddle [18], who also found a negative relationship between population density and pollutant emissions. The energy intensity and the proportion of industrial and tertiary industry output had a positive impact on solid waste production in the three regions. Specifically, the elasticity of solid waste production to industrial output in the central region was 1.49 , greater than in the western region (1.46) or in the eastern region (1.15). Similar to the industrial output, the impact of the proportion of the tertiary industry output on solid waste production in the central region was greater than that in the eastern and western regions. A $1 \%$ increase in industrial energy intensity increased solid waste production by $0.73 \%, 0.13 \%$ and $0.25 \%$ in eastern central and western China, respectively. Interestingly, both per capita income and its squared value for the three regions were found to be statistically significant at the $5 \%$ level or lower. Solid waste production first decreased sharply and then increased with wealth, demonstrating a U-shaped relationship between economic growth and solid waste production at the regional scales.

It can be seen that the effect of the increase in population density on per capita energy consumption and pollutant emissions in China varied across regions (Figs. 3 and 4). For the entire country, higher population density decreased energy consumption and the emissions of industrial exhaust gases and wastewater but increased solid waste production. At the regional scale, elevated population density decreased energy demand and exhaust gas emissions and solid waste production but increased wastewater discharge in the three regions. Economic growth promoted to the increase in energy consumption in the eastern and western regions, but it decreased exhaust gas emissions and solid waste production in the three regions. Further economic development would increase the emissions of two types of pollutants in the three regions. Economic development first decreased wastewater

Table 6

Estimation results for per capita industrial wastewater discharge by DK models, $95 \%$ confidence intervals in brackets.

\begin{tabular}{|c|c|c|c|c|}
\hline Variable & Whole of China & Eastern region & Central region & Western region \\
\hline $\operatorname{Ln}(\mathrm{POPD})$ & $0.127^{* * * *}[0.09 \quad 0.16]$ & $0.209^{* * * *}[0.12 \quad 0.30]$ & $0.134^{* *}\left[\begin{array}{ll}0.01 & 0.26\end{array}\right]$ & $0.132^{* * *}[0.04 \quad 0.23]$ \\
\hline $\operatorname{Ln}(\mathrm{pGDP})$ & $0.153[-1.32 \quad 1.63]$ & $1.162[-0.34 \quad 2.67]$ & $-1.455^{*}\left[\begin{array}{ll}-3.15 & 0.23\end{array}\right]$ & $-0.334\left[\begin{array}{ll}-3.32 & 2.65\end{array}\right]$ \\
\hline $\operatorname{Ln}(\mathrm{pGDP})^{2}$ & $0.004[-0.08 \quad 0.09]$ & $-0.067[-0.15 \quad 0.01]$ & $0.083^{*}[-0.01 \quad 0.18]$ & $0.043[-0.13 \quad 0.21]$ \\
\hline $\operatorname{Ln}(\mathrm{INDU})$ & $0.188^{* * *}[0.11 \quad 0.27]$ & $1.046^{* * * *}[0.85 \quad 1.25]$ & $-0.419\left[\begin{array}{ll}-0.86 & 0.03\end{array}\right]$ & $-0.466\left[\begin{array}{ll}-1.29 & 0.35\end{array}\right]$ \\
\hline $\operatorname{Ln}(\mathrm{TERT})$ & $-0.583^{* * * *}\left[\begin{array}{ll}-0.99 & -0.18\end{array}\right]$ & $-0.171[-0.65 \quad 0.30]$ & $-0.506^{*}\left[\begin{array}{ll}-1.02 & 0.01\end{array}\right]$ & $-0.796[-2.19 \quad 0.60]$ \\
\hline $\operatorname{Ln}(\mathrm{IEI})$ & $0.142^{* * *}[0.04 \quad 0.24]$ & $0.106[-0.12 \quad 0.33]$ & $-0.006[-0.04 \quad 0.02]$ & $0.304^{* * *}\left[\begin{array}{ll}0.07 & 0.54\end{array}\right]$ \\
\hline Constant & $1.710[-5.86 \quad 9.28]$ & $-6.542^{*}[-13.620 .54]$ & $13.027^{* * * *}[8.40 \quad 17.66]$ & $5.806\left[\begin{array}{ll}-5.40 & 17.01\end{array}\right]$ \\
\hline CIPS & $I(0)$ & $I(0)$ & $I(0)$ & $I(0)$ \\
\hline Mean rho & 0.25 & 0.18 & 0.16 & 0.43 \\
\hline $\mathrm{CD}(p)$ & $3.47(0.18)$ & $5.97(0.24)$ & $4.74(0.26)$ & $4.61(0.08)$ \\
\hline$R^{2}$ & 0.219 & 0.262 & 0.839 & 0.116 \\
\hline Obs & 690 & 253 & 184 & 184 \\
\hline
\end{tabular}

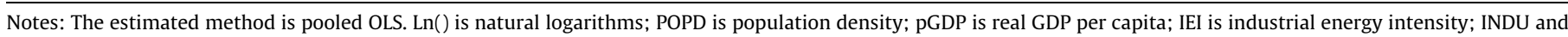

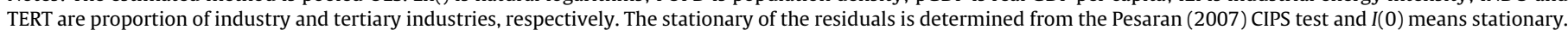

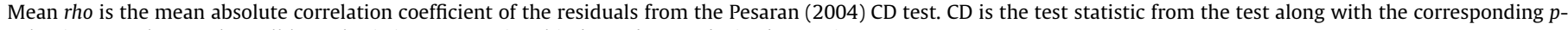
value in parentheses. The null hypothesis is cross-sectional independence. Obs is observations.

* Indicate statistical significance at the $10 \%$ level.

** Indicate statistical significance at the $5 \%$ level.

${ }^{* * *}$ Indicate statistical significance at the $1 \%$ level. 
Table 7

Estimation results for per capita industrial solid waste production by DK models, $95 \%$ confidence intervals in brackets.

\begin{tabular}{|c|c|c|c|c|}
\hline Variable & Whole of China & Eastern region & Central region & Western region \\
\hline $\operatorname{Ln}(\mathrm{POPD})$ & $-0.338^{* * * *}[-0.42 \quad-0.26]$ & $-0.421^{* * *}[-0.51 \quad-0.33]$ & $-0.216^{* *}[-0.40 \quad-0.03]$ & $-0.065^{* *}[-0.13 \quad 0.00]$ \\
\hline $\operatorname{Ln}(\mathrm{pGDP})$ & $-0.440[-2.46 \quad 1.58]$ & $-3.090^{* * *}\left[\begin{array}{ll}-5.63 & -0.55\end{array}\right]$ & $-3.771^{* * * * *}[-6.14 \quad-1.40]$ & $-3.529^{* * * *}\left[\begin{array}{ll}-4.53 & -2.53\end{array}\right]$ \\
\hline $\operatorname{Ln}(\mathrm{pGDP})^{2}$ & $0.059[-0.06 \quad 0.17]$ & $0.225^{* * *}\left[\begin{array}{ll}0.09 & 0.36\end{array}\right]$ & $0.248^{* * *}[0.11 \quad 0.39]$ & $0.259^{* * *}[0.20 \quad 0.32]$ \\
\hline $\operatorname{Ln}(\mathrm{INDU})$ & $0.971^{* * *}[0.88 \quad 1.06]$ & $1.148^{* * *}[0.81 \quad 1.49]$ & $1.490^{* * *}[0.62 \quad 2.36]$ & $1.416^{* * * *}[0.951 .89]$ \\
\hline $\operatorname{Ln}(\mathrm{TERT})$ & $0.339[-0.07 \quad 0.75]$ & $0.750^{* * *}[0.15 \quad 1.35]$ & $1.561^{* * * *}[0.75 \quad 2.38]$ & $0.714^{* *}[-0.11 \quad 1.54]$ \\
\hline $\operatorname{Ln}(\mathrm{IEI})$ & $0.151^{* * * *}\left[\begin{array}{ll}0.09 & 0.21\end{array}\right]$ & $0.734^{* * * *}[0.35 \quad 1.12]$ & $0.126^{* * * *}[0.06 \quad 0.19]$ & $0.251^{* * * *}[0.11 \quad 0.39]$ \\
\hline Constant & $-3.867\left[\begin{array}{ll}-11.61 & 3.87\end{array}\right]$ & $4.235[-6.43 \quad 14.90]$ & $3.996[-6.78 \quad 14.77]$ & $3.607^{* *}\left[\begin{array}{ll}0.0 & 17.21\end{array}\right]$ \\
\hline CIPS & $I(0)$ & $I(0)$ & $I(0)$ & $I(0)$ \\
\hline Mean rho & 0.19 & 0.17 & 0.19 & 0.25 \\
\hline $\mathrm{CD}(p)$ & $18.99(0.14)$ & $2.78(0.25)$ & $1.83(0.10)$ & $3.02(0.34)$ \\
\hline$R^{2}$ & 0.543 & 0.620 & 0.521 & 0.704 \\
\hline Obs & 690 & 253 & 184 & 184 \\
\hline
\end{tabular}

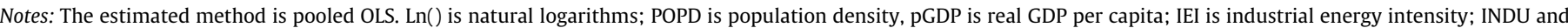

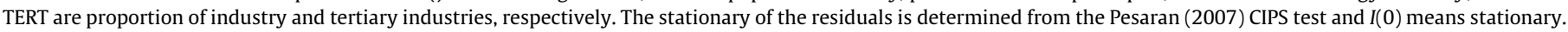

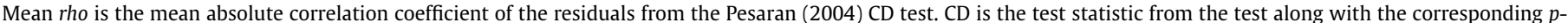
value in parentheses. The null hypothesis is cross-sectional independence. Obs is observations.

** Indicate statistical significance at the $5 \%$ level.

**** Indicate statistical significance at the $1 \%$ level.

Table 8

Relationships between economic growth and three types of industrial pollutant emissions (whole country sample and eastern, central and western regions).

\begin{tabular}{|c|c|c|c|}
\hline Sample & Exhaust gases & Waste water & Solid waste \\
\hline Whole of China & Not obvious ${ }^{\mathrm{a}}$ & Not obvious & Not obvious \\
\hline Eastern region & Not obvious & Not obvious & U-shaped \\
\hline Central region & U-shaped & U-shaped & U-shaped \\
\hline Western region & U-shaped & Not obvious & U-shaped \\
\hline
\end{tabular}

Notes: The results obtained from the above DK models are based on the estimated coefficients for per capita income and their squared values.

a Not obvious means that the estimated coefficients for income per capita and their squared terms were not statistically significant at the $10 \%$ level or higher.

discharge but then increased discharge in the central region over time. The proportion of industrial output and tertiary industry output had positive influences on energy consumption and solid waste emissions in the three regions, but their impact on wastewater discharge varied across regions. These findings also further confirmed the fact that the impact of population, affluence and technology on pollutant emissions depended on the level of development and the type of pollutants $[13,39]$. To reduce pollutant emissions, we should exchange the former pattern of high pollution and energy use for economic growth. Meanwhile, we should comprehensively consider the factors affecting the discharge of industrial pollutants and develop effective emission reduction measures to realise the sustainable development of population, resources and environment.

\subsection{The EKC relationships between per capita income and industrial pollutant emissions}

The relationship between economic growth and environmental quality depended on the type of pollutants in China. The abovementioned DK model estimates suggested that the EKC relationship between economic development and emissions of three industrial wastes were not obvious (Table 8). This result was supported by Managi and Kaneko [60], who suggested that no single relationship existed between environmental quality and income per capita. However, our findings did not in agree with those of a previous study that showed that inverted U-shaped relationships existed for industrial exhaust gases, wastewater and solid waste in China [26]. The possible reason behind this difference is that we also considered additional impact factors (e.g., demographic changes, industrial structures, and industrial energy intensity) on pollutant emissions, in addition to economic growth.
The relationship between economic growth and industrial pollutant emissions were also heterogeneous across regions and depended on the type of pollutants (Table 8). In eastern China, a U-shaped relationship was found for solid waste. However, the linkages between per capita incomes and exhaust gases as well as wastewater discharge were not obvious. In central China, there were U-shaped relations between per capita incomes and three industrial wastes. In western China, U-shaped relationships existed between per capita incomes and exhaust gases or solid waste.

\section{Conclusions and policy implications}

Based on a balanced and high-quality panel data covering 30 provinces of China for the period 1990-2012, this study used an extended STIRPAT model to assess the population, income and technology impact on energy consumption and three types of industrial pollutant emissions in whole of China and its three parts (eastern, central and western regions). The results of the second-generation panel unit root tests suggested that all variables in this study were integrated of order one. Generally, higher population density decreased energy consumption in China but its effect on industrial pollutant emissions varied across the three regions in China. Specifically, higher population density not only contributed to the increase in the discharge of industrial wastewater but also led to the decrease in solid waste production in China and its three regions.

The effects of technology factors on energy consumption and pollutant emissions in China also showed an apparent heterogeneity across regions. The proportion of industrial output had a significant and positive influence on energy consumption and industrial pollutant emissions in whole of China and its three regions. The proportion of the tertiary industry output was also positively correlated with energy consumption in the three regions of China, but its impact on industrial exhaust gas emissions was insignificant. These results demonstrated that improving energy intensity, changing the energy consumption structure and upgrading industrial structures may still be necessary and useful to mitigate the emission of industrial pollutants in China.

The relationship between economic growth and environmental impact depended on the type of pollutants and differed across regions as well. No strong evidence was found to support the existence of the EKC hypothesis between three industrial waste emissions and incomes per capita at the regional scale. However, U-shaped curves existed for solid waste production in the eastern 
region, three industrial wastes in the central region, and exhaust gases and solid waste in the western region.

Our empirical results will be of special interest to policy makers and urban planners in China. Urbanisation is expected to continue to be one of the primary driving forces for future economic growth in China. Currently, the Chinese government proposes a people-oriented urbanisation concept in the National New Type Urbanisation Plan (2014-2020). One of the important targets of new-type urbanisation is to gradually settle the rural population that has migrated to cities, which will inevitably require additional urban infrastructure and possibly more energy resources and thus results in the emission of more pollutants. It is thus essential for the government of China to take measures to control the pace of the urbanisation process, to develop more sustainable infrastructure systems, and to improve energy efficiency as well as upgrade industrial and production structures. In the context of such rapid industrialisation and urbanisation, policy-makers also require more detailed information about the complex linkages between human activities and environmental impact. Moreover, urban planning and management policymakers should take regional pollutant reduction priorities into consideration. Considering the strongest impact of population, income and technology on pollutant emissions, eastern China should focus its efforts on industrial wastewater and exhaust gases, whereas central and western China should pay more attention to solid waste.

\section{Acknowledgments}

The work has been financially supported by the National Natural Science Foundation of China (Grant Nos. 41130748 and 41471143) and the National Science \& Technology Pillar Program during the Twelfth Five-Year Plan Period (Grant Nos. 2014BAL01B01 and 2014BAL01B05). Cordial thanks should give to two helpful and constructive reviewers whose comments greatly improved our manuscript, as did the comments and encouragements of the Editor-in-Chief (Professor J. Yan).

\section{Appendix A}

Fig. A.1 shows the eastern, central and western regions of China. The eastern region includes Liaoning, Beijing, Tianjin, Hebei,

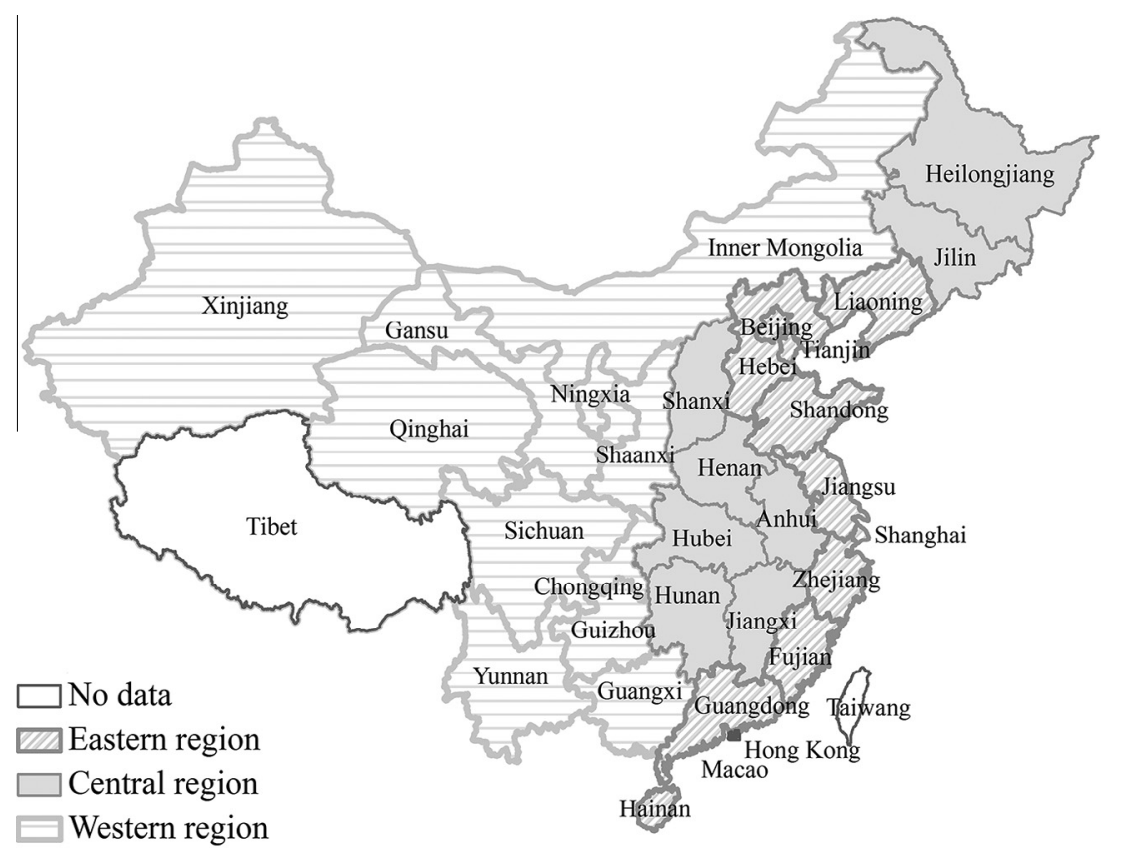

Fig. A.1. Eastern, central and western regions of China.

Table A.1

Pesaran (2007) panel unit root tests for 31 provincial samples.

\begin{tabular}{|c|c|c|c|c|c|c|c|c|c|c|c|c|}
\hline \multirow[t]{3}{*}{ No. lags } & \multicolumn{6}{|c|}{ Variables in levels } & \multicolumn{6}{|c|}{ Variables in first differences } \\
\hline & \multicolumn{3}{|c|}{ Constant } & \multicolumn{3}{|c|}{ Constant and Trend } & \multicolumn{3}{|c|}{ Constant } & \multicolumn{3}{|c|}{ Constant and Trend } \\
\hline & 1 & 2 & 3 & 1 & 2 & 3 & 1 & 2 & 3 & 1 & 2 & 3 \\
\hline $\operatorname{Ln}(E C)$ & 0.289 & 0.772 & 0.953 & 0.863 & 0.939 & 0.917 & 0.000 & 0.006 & 0.008 & 0.000 & 0.174 & 0.182 \\
\hline $\operatorname{Ln}(\mathrm{IEI})$ & 0.000 & 0.004 & 0.041 & 0.917 & 0.586 & 0.722 & 0.000 & 0.000 & 0.031 & 0.000 & 0.000 & 0.674 \\
\hline $\operatorname{Ln}(\mathrm{FQ})$ & 0.353 & 0.931 & 0.847 & 0.166 & 0.761 & 0.687 & 0.000 & 0.000 & 0.083 & 0.000 & 0.072 & 0.667 \\
\hline $\operatorname{Ln}(\mathrm{FS})$ & 0.792 & 0.949 & 0.815 & 1.000 & 1.000 & 1.000 & 0.000 & 0.105 & 0.786 & 0.000 & 0.927 & 1.000 \\
\hline $\operatorname{Ln}(\mathrm{FW})$ & 0.916 & 0.987 & 0.930 & 0.612 & 0.993 & 0.989 & 0.000 & 0.000 & 0.051 & 0.000 & 0.268 & 0.960 \\
\hline $\operatorname{Ln}(\mathrm{POPD})$ & 0.864 & 0.920 & 0.998 & 0.999 & 0.997 & 1.000 & 0.012 & 0.029 & 0.843 & 0.009 & 0.071 & 1.000 \\
\hline $\operatorname{Ln}(\mathrm{pGDP})$ & 0.953 & 0.994 & 1.000 & 0.984 & 0.997 & 1.000 & 0.009 & 0.028 & 0.823 & 0.005 & 0.019 & 0.396 \\
\hline Ln(INDU) & 0.024 & 0.451 & 0.101 & 0.259 & 0.871 & 0.202 & 0.000 & 0.000 & 0.000 & 0.000 & 0.025 & 0.063 \\
\hline Ln(TERT) & 0.660 & 0.976 & 0.713 & 0.449 & 0.990 & 0.370 & 0.000 & 0.008 & 0.014 & 0.000 & 0.308 & 0.934 \\
\hline
\end{tabular}

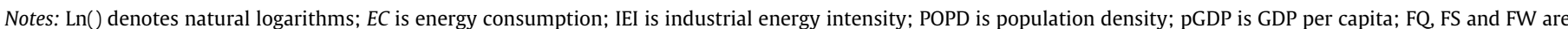

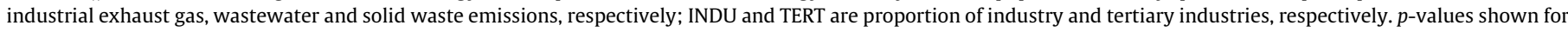
null hypothesis of $I(1)$. 
Table A.2

Estimation results for energy use by FE and FGLS models (whole sample and eastern, central and western regions).

\begin{tabular}{|c|c|c|c|c|c|c|c|c|}
\hline \multirow[t]{2}{*}{ Variable } & \multicolumn{2}{|c|}{ Whole of China } & \multicolumn{2}{|c|}{ Eastern region } & \multicolumn{2}{|c|}{ Central region } & \multicolumn{2}{|c|}{ Western region } \\
\hline & FE (1) & FGLS (2) & $\mathrm{FE}(3)$ & FGLS (4) & FE (5) & FGLS (6) & FE (7) & FGLS (8) \\
\hline $\operatorname{Ln}(\mathrm{POPD})$ & $0.24^{* *}$ & $0.21^{* * * *}$ & -0.02 & $-0.07^{* * *}$ & $-0.79^{*}$ & $-0.28^{* * *}$ & 0.49 & $-0.21^{* * *}$ \\
\hline $\operatorname{Ln}(\mathrm{pGDP})$ & $0.61^{* * *}$ & $0.56^{* * *}$ & $0.59^{* * * *}$ & $0.46^{* * *}$ & $0.67^{* * *}$ & $0.32^{* * *}$ & $0.62^{* * *}$ & $0.43^{* * *}$ \\
\hline $\operatorname{Ln}(\mathrm{INDU})$ & $0.59^{* * *}$ & $0.52^{* * *}$ & $0.99^{* * * *}$ & $0.94^{* * *}$ & 0.05 & $1.43^{* * * *}$ & $0.56^{* * *}$ & $1.38^{* * *}$ \\
\hline Ln(TERT) & -0.120 & $0.96^{* * *}$ & $0.48^{* * *}$ & $1.44^{* * *}$ & $-0.61^{* * * *}$ & $0.86^{* * *}$ & -0.02 & $0.73^{* * *}$ \\
\hline Constant & $-7.75^{* *}$ & $-8.47^{* *}$ & $-10.0^{* *}$ & $-11.89^{* * * *}$ & -1.100 & $-9.11^{* * * *}$ & $-8.72^{* * *}$ & $-9.73^{* * *}$ \\
\hline$R^{2}$ & 0.904 & - & 0.915 & - & 0.912 & - & 0.924 & - \\
\hline AC test & \multicolumn{2}{|c|}{$F(1,29)=167.36^{* * *}$} & \multicolumn{2}{|c|}{$F(1,10)=56.2^{* * *}$} & \multicolumn{2}{|c|}{$F(1,7)=32.05^{* * * *}$} & \multicolumn{2}{|c|}{$F(1,10)=105.83^{* * *}$} \\
\hline CD test & \multicolumn{2}{|c|}{$20.91^{* * * *}$} & \multirow{2}{*}{\multicolumn{2}{|c|}{$\begin{array}{l}7.03^{* * *} \\
x^{2}(11)=449.44^{* * *}\end{array}$}} & \multirow{2}{*}{\multicolumn{2}{|c|}{$\begin{array}{l}9.17^{* * *} \\
x^{2}(8)=65.11^{* * * *}\end{array}$}} & \multicolumn{2}{|c|}{$6.31^{* * * *}$} \\
\hline HK test & \multicolumn{2}{|c|}{$x^{2}(30)=1402.75^{* * *}$} & & $x^{2}(11)=449.44^{* * *}$ & & $x^{2}(8)=65.11^{* * * *}$ & \multicolumn{2}{|c|}{$x^{2}(11)=520.11^{* * * *}$} \\
\hline Obs & 690 & 690 & 253 & 253 & 184 & 184 & 253 & 253 \\
\hline
\end{tabular}

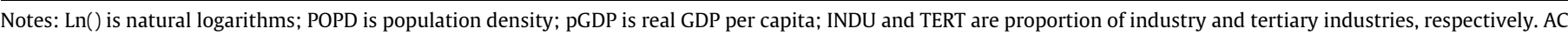
is autocorrelation; CD is cross-sectional dependence; HK is heteroskedasticity; Obs is observations. FE (Fixed Effects); FGLS (Feasible Generalized Least Squares).

* Indicate significance at the $10 \%$ level.

*** Indicate significance at the $5 \%$ level.

${ }^{* * *}$ Indicate significance at the $1 \%$ level.

Table A.3

Estimation results for industrial pollutant emissions by FE and FGLS models (whole sample and eastern, central and western regions).

\begin{tabular}{|c|c|c|c|c|c|c|c|c|}
\hline \multirow[t]{3}{*}{ Variable } & \multicolumn{2}{|c|}{ Whole of China } & \multicolumn{2}{|c|}{ Eastern region } & \multicolumn{2}{|c|}{ Central region } & \multicolumn{2}{|c|}{ Western region } \\
\hline & \multicolumn{8}{|c|}{ Industrial exhaust gases } \\
\hline & $\mathrm{FE}(9)$ & FGLS (10) & $\mathrm{FE}(11)$ & FGLS (12) & $\mathrm{FE}(13)$ & FGLS (14) & $\mathrm{FE}(15)$ & FGLS (16) \\
\hline $\operatorname{Ln}(\mathrm{POPD})$ & 0.08 & $-0.21^{* * *}$ & -0.29 & $-0.09^{* * *}$ & $2.47^{* * *}$ & $-0.09^{* * *}$ & $1.68^{* * *}$ & $-0.07^{* * * *}$ \\
\hline $\operatorname{Ln}(\mathrm{pGDP})$ & 0.33 & 0.06 & -0.67 & -0.20 & $-2.24^{* * *}$ & $-3.02^{* * *}$ & $-1.87^{* *}$ & $-2.41^{* * * *}$ \\
\hline $\operatorname{Ln}(p G D P)^{2}$ & $0.04^{* * * *}$ & $0.06^{* * * *}$ & 0.09 & $0.08^{* * * *}$ & $0.18^{* * *}$ & $0.22^{* * * *}$ & $0.18^{* * * *}$ & $0.22^{* * *}$ \\
\hline $\operatorname{Ln}(\mathrm{INDU})$ & $0.72^{* * *}$ & $0.55^{* * *}$ & $0.98^{* * * *}$ & $0.89^{* * * *}$ & 0.29 & $1.85^{* * *}$ & 0.06 & $0.47^{* * *}$ \\
\hline $\operatorname{Ln}(\mathrm{TERT})$ & $-0.46^{* * *}$ & $0.19^{* * *}$ & -0.08 & $0.30^{* * * *}$ & $-0.79^{* * * *}$ & $1.24^{* * *}$ & -0.18 & $0.40^{* * *}$ \\
\hline $\operatorname{Ln}(\mathrm{IEI})$ & $0.10^{* * * *}$ & $0.33^{* * *}$ & $0.18^{* * *}$ & $0.59^{* * * *}$ & 0.01 & $0.12^{* * * *}$ & $0.17^{* * * *}$ & $0.51^{* * * *}$ \\
\hline Constant & $2.69^{* *}$ & $3.12^{* * * *}$ & $6.71^{* * *}$ & 1.246 & 3.62 & $8.58^{* * *}$ & $5.99^{* *}$ & $11.07^{* * *}$ \\
\hline$R^{2}$ & 0.885 & - & 0.897 & - & 0.907 & - & 0.907 & - \\
\hline AC test & $F(1,29)=$ & & $F(1,10)=$ & & $F(1,7)=$ & & $F(1,10)=$ & \\
\hline CD test & $20.36^{* * *}$ & & $6.25^{* * * *}$ & & $4.96^{* * *}$ & & $4.60^{* * * *}$ & \\
\hline HK test & $x^{2}(30)=3$ & & $x^{2}(11)=2$ & & $x^{2}(8)=15$ & & $x^{2}(11)=1$ & \\
\hline Obs & 690 & 690 & 253 & 253 & 184 & 184 & 253 & 253 \\
\hline \multirow[t]{2}{*}{ Variable } & \multicolumn{8}{|c|}{ Industrial wastewater } \\
\hline & FE (17) & FGLS (18) & FE (19) & FGLS (20) & $\mathrm{FE}(21)$ & FGLS (22) & FE (23) & FGLS (24) \\
\hline $\operatorname{Ln}(\mathrm{POPD})$ & $-1.56^{* * *}$ & $0.13^{* * * *}$ & $-2.75^{* * *}$ & $0.21^{* * *}$ & 0.55 & $-0.14^{* * *}$ & $1.33^{* * *}$ & $0.12^{* * *}$ \\
\hline $\operatorname{Ln}(\mathrm{pGDP})$ & $-1.46^{* * *}$ & $0.16^{* * *}$ & $-2.23^{* * *}$ & $1.03^{* * *}$ & $-1.55^{* * *}$ & $-1.59^{* * *}$ & $-3.31^{* * *}$ & $-0.66^{* *}$ \\
\hline $\operatorname{Ln}(p G D P)^{2}$ & $0.09^{* * *}$ & 0.01 & $0.14^{* * *}$ & $-0.06^{* * *}$ & $0.09^{* * *}$ & $0.09^{* * *}$ & $0.19^{* * * *}$ & $0.06^{* * *}$ \\
\hline $\operatorname{Ln}($ INDU) & $0.98^{* * *}$ & $0.19^{* * * *}$ & $1.45^{* * * *}$ & $1.07^{* * *}$ & 0.18 & $-0.36^{* * *}$ & 0.35 & $-0.46^{* * *}$ \\
\hline $\operatorname{Ln}(\mathrm{TERT})$ & -0.05 & -0.57 & $0.78^{* * * *}$ & $-0.11^{* *}$ & $-0.91^{* * * *}$ & $-0.38^{* * * *}$ & 0.11 & $-0.61^{* * *}$ \\
\hline $\operatorname{Ln}(\mathrm{IEI})$ & $0.12^{* * *}$ & $0.14^{* * *}$ & $0.19^{* * *}$ & $0.07^{* * * *}$ & $0.06^{* * *}$ & 0.00 & -0.04 & $0.25^{* * *}$ \\
\hline Constant & $13.57^{* * *}$ & $1.64^{* * * *}$ & $20.82^{* * * *}$ & $-5.98^{* * *}$ & $8.78^{* * *}$ & $13.04^{* * * *}$ & $9.47^{* * *}$ & $6.82^{* * *}$ \\
\hline$R^{2}$ & 0.361 & - & 0.685 & - & 0.581 & - & 0.167 & - \\
\hline AC test & $F(1,29)=$ & & $F(1,10)=$ & & $F(1,7)=$ & & $F(1,10)=$ & \\
\hline CD test & $3.73^{* * *}$ & & $6.25^{* * *}$ & & $4.78^{* * *}$ & & $4.60^{* * * *}$ & \\
\hline HK test & $x^{2}(30)=$ & & $x^{2}(11)=$ & & $x^{2}(8)=1$ & & $x^{2}(11)=$ & \\
\hline Obs & 690 & 690 & 253 & 253 & 184 & 184 & 253 & 253 \\
\hline \multirow[t]{2}{*}{ Variable } & \multicolumn{8}{|c|}{ Industrial solid waste } \\
\hline & FE (25) & FGLS (26) & $\mathrm{FE}(27)$ & FGLS (28) & FE (29) & FGLS (30) & $\mathrm{FE}(31)$ & FGLS (32) \\
\hline $\operatorname{Ln}(\mathrm{POPD})$ & $-0.31^{*}$ & $-0.34^{* * * *}$ & $-1.14^{* * *}$ & $-0.42^{* * * *}$ & $2.08^{* * *}$ & $-0.25^{* * *}$ & $2.06^{* * *}$ & $-0.06^{* * *}$ \\
\hline $\operatorname{Ln}(\mathrm{pGDP})$ & -0.33 & $-0.42^{* * *}$ & $-3.06^{* * * *}$ & $-2.83^{* * *}$ & $-2.41^{* * *}$ & $-3.10^{* * * *}$ & $-3.43^{* * *}$ & $-3.76^{* * *}$ \\
\hline $\operatorname{Ln}(\mathrm{pGDP})^{2}$ & $0.06^{* * * *}$ & $0.06^{* * *}$ & $0.21^{* * *}$ & $0.21^{* * *}$ & $0.18^{* * *}$ & $0.21^{* * * *}$ & $0.25^{* * *}$ & 0.27 \\
\hline $\operatorname{Ln}(\mathrm{INDU})$ & $0.86^{* * *}$ & $0.97^{* * *}$ & $0.89^{* * *}$ & $1.14^{* * *}$ & 0.10 & $1.30^{* * * *}$ & 0.46 & 1.27 \\
\hline $\operatorname{Ln}(\mathrm{TERT})$ & -0.13 & $0.34^{* * *}$ & 0.02 & $0.77^{* * * *}$ & $-0.70^{* * *}$ & $1.23^{* * *}$ & 0.39 & 0.69 \\
\hline $\operatorname{Ln}($ IEI $)$ & $0.08^{* * * *}$ & $0.15^{* * *}$ & 0.07 & $0.67^{* * *}$ & 0.01 & $0.11^{* * * *}$ & $0.13^{* *}$ & 0.21 \\
\hline Constant & $-2.99^{*}$ & $-3.93^{* * *}$ & $13.52^{\text {***** }}$ & $3.28^{* * *}$ & -2.08 & $3.02^{*}$ & -1.24 & 5.31 \\
\hline$R^{2}$ & 0.305 & - & 0.792 & - & 0.879 & - & 0.827 & - \\
\hline AC test & \multicolumn{2}{|c|}{$F(1,29)=102.46^{* * *}$} & \multicolumn{2}{|c|}{$F(1,10)=42.04^{* * *}$} & \multicolumn{2}{|c|}{$F(1,7)=1.65^{* * *}$} & \multicolumn{2}{|c|}{$F(1,10)=163.37^{* * *}$} \\
\hline CD test & \multicolumn{2}{|c|}{$20.39^{* * * *}$} & \multirow{2}{*}{\multicolumn{2}{|c|}{$\begin{array}{l}2.95^{* * *} \\
x^{2}(11)=1143.99^{* * *}\end{array}$}} & \multirow{2}{*}{\multicolumn{2}{|c|}{$\begin{array}{l}1.91^{* * *} \\
x^{2}(8)=48.27^{* * *}\end{array}$}} & \multicolumn{2}{|c|}{$3.43^{* * *}$} \\
\hline HK test & \multicolumn{2}{|c|}{$x^{2}(30)=3284^{* * *}$} & & & & & $x^{2}(11)=5$ & \\
\hline Obs & 690 & 690 & 253 & 253 & 184 & 184 & 253 & 253 \\
\hline
\end{tabular}

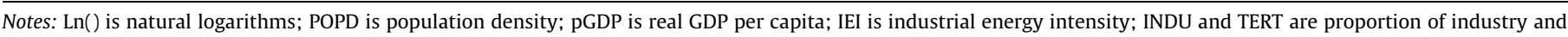

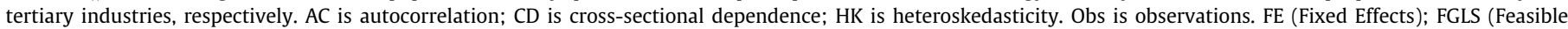
Generalized Least Squares).

* Indicate significance at the $10 \%$ level.

** Indicate significance at the 5\% level.

**** Indicate significance at the $1 \%$ level. 
Table A.4

VIF tests for multicollinearity.

\begin{tabular}{|c|c|c|c|c|c|c|c|c|c|c|c|c|}
\hline & Model 1 & Model 3 & Model 5 & Model 7 & Model 9 & Model 11 & Model 13 & Model 15 & Model 33 & Model 35 & Model 37 & Model 24 \\
\hline POPD & 1.25 & 1.38 & 1.07 & 1.11 & 1.35 & 1.38 & 1.08 & 1.5 & 1.72 & 1.46 & 1.18 & 1.52 \\
\hline pGDP & 2.14 & 2.34 & 2.82 & 2.98 & 3.52 & 4.61 & 4.09 & 5.15 & 5.2 & 8.25 & 4.43 & 7.37 \\
\hline INDU & 1.80 & 1.78 & 2.06 & 2.21 & 1.83 & 1.81 & 2.17 & 2.32 & 2.18 & 4.14 & 3.59 & 2.42 \\
\hline TERT & 2.34 & 2.97 & 2.29 & 1.71 & 2.44 & 3.08 & 2.32 & 1.87 & 2.45 & 3.34 & 2.71 & 1.87 \\
\hline IEI & - & - & - & - & 2.21 & 2.67 & 1.81 & 2.38 & 2.57 & 4.08 & 2.10 & 3.25 \\
\hline Mean & 1.88 & 2.12 & 2.06 & 2.00 & 2.27 & 2.71 & 2.29 & 2.64 & 2.76 & 4.48 & 2.96 & 3.21 \\
\hline
\end{tabular}

Notes: The VIF values are all below than 10, indicating that there is no multicollinearity (all variables in natural logarithms).

Shandong, Jiangsu, Shanghai, Zhejiang, Guangdong, Fujian and Hainan provinces; the central region includes Heilongjiang, Jilin, Shanxi, Henan, Anhui, Jiangxi, Hubei and Hunan provinces; and the western region includes Xinjiang, Gansu, Qinghai, Inner Mongolia, Ningxia, Shaanxi, Sichuan, Chongqing, Guizhou, Yunnan and Guangxi provinces. It is generally accepted that the eastern area of China belongs to the developed region, and the western and central regions are the underdeveloped or less developed region.

See Tables A.1-A.4.

\section{References}

[1] Liu J, Diamond J. China's environment in a globalizing world. Nature 2005;435:1179-86.

[2] Shao M, Tang X, Zhang Y, Li W. City clusters in China: air and surface water pollution. Front Ecol Environ 2006;4:353-61.

[3] Peters GP, Weber CL, Guan D, Hubacek K. China's growing $\mathrm{CO}_{2}$ emissions a race between increasing consumption and efficiency gains. Environ Sci Technol 2007;41(17):5939-44.

[4] Chang C. A multivariate causality test of carbon dioxide emissions, energy consumption and economic growth in China. Appl Energy 2010:87(11):3533-7.

[5] Wang K, Wei Y, Zhang X. Energy and emissions efficiency patterns of Chinese regions: a multi-directional efficiency analysis. Appl Energy 2013;104:105-16.

[6] Hsu A, Emerson J, Levy M, Sherbinin A, Johnson L, Malik O, Schwartz J, Jaiteh M. The 2014 Environmental Performance Index. New Haven, CT: Yale Center for Environmental Law \& Policy; 2014. <http://www.epi.yale.edu>.

[7] National Environmental Protection Agency. China Environmental Yearbook, Beijing; 1996.

[8] Cheng H, Zhang Y, Meng A, Li Q. Municipal solid waste fueled power generation in China: a case study of waste-to-energy in Changchun city. Environ Sci Technol 2007:41:7509-15.

[9] Ministry of Environmental Protection, National Bureau of Statistics and Ministry of Agriculture of China. The First National Survey of Pollution Sources Bulletin (in Chinese). 2010. <http://www.gov.cn/jrzg/2010-02/ 10/content_1532174.htm> [accessed 25.4.14]

[10] World Bank. Cost of pollution in China: economic estimates of physical damages. Washington, DC: World Bank; 2007.

[11] United Nations (UN). World urbanization prospects: the 2014 revision. UN, New York, 2014

[12] Poumanyvong P, Kaneko S. Does urbanization lead to less energy use and lower $\mathrm{CO}_{2}$ emissions? A cross-country analysis. Ecol Econ 2010;70(2):434-44.

[13] Fan Y, Liu LC, Wu G, Wei Y. Analyzing impact factors of $\mathrm{CO}_{2}$ emissions using the STIRPAT model. Environ Impact Assess Rev 2006;26(4):377-95.

[14] Lin B, Sun B. Evaluating carbon dioxide emissions in international trade of China. Energy Policy 2010;8:613-21.

[15] York R, Rosa EA, Dietz T. STIRPAT, IPAT and ImPACT: analytic tools for unpacking the driving forces of environmental impacts. Ecol Econ 2003;46(3):351-65.

[16] $\mathrm{Xu} \mathrm{S}$, He Z, Long R. Factors that influence carbon emissions due to energy consumption in China: Decomposition analysis using LMDI. Appl Energy 2014;127:182-93.

[17] Liddle B. Demographic dynamics and per capita environmental impact: using panel regressions and household decompositions to examine population and transport. Popul Environ 2004;26:23-9.

[18] Liddle B. Impact of population, age structure, and urbanization on carbon emissions/energy consumption: evidence from macro-level, cross-country analysis. Popul Environ 2014;35:286-304.

[19] Liddle B, Lund S. Age-structure, urbanization, and climate change in developed countries: revisiting STIRPAT fore disaggregated population and consumptionrelated environmental impacts. Popul Environ 2010;31:317-43.

[20] Shi A. The impact of population pressure on global carbon dioxide emissions, 1975-1996: evidence from pooled cross-country data. Ecol Econ 2003;44(1):29-42.

[21] O'Neill BC, Liddle B, Jiang L, Smith KR, Pachauri S, Dalton M, et al. Demographic change and carbon dioxide emissions. Lancet 2012;380:157-64.
[22] Jalil A, Mahmud SF. Environment Kuznets curve for $\mathrm{CO}_{2}$ emissions: a cointegration analysis for China. Energy Policy 2009;37(12):5167-72.

23] Liddle B. Population, affluence, and environmental impact across development: evidence from panel cointegration modeling. Environ Model Softw 2013;40:255-66.

[24] Liddle B. What are the carbon emissions elasticities for income and population? Bridging STIRPAT and EKC via robust heterogeneous panel estimates. Global Environ Chang 2015;31:62-73.

[25] Shen JY. A simultaneous estimation of environmental Kuznets curve: evidence from China. China Econ Rev 2006;17(4):383-94.

[26] Song T, Zheng T, Tong L. An empirical test of the environmental Kuznets curve in China: a panel cointegration approach. China Econ Rev 2008;19:381-92.

[27] Wang S, Zhou D, Zhou P, Wang Q. $\mathrm{CO}_{2}$ emissions, energy consumption and economic growth in China: a panel data analysis. Energy Policy $2011 ; 39(9): 4870-5$.

[28] Wang Z, Yin F, Zhang Y, Li N. An empirical research on the influencing factors of regional $\mathrm{CO}_{2}$ emissions: evidence from Beijing city, China. Appl Energy 2012;100:277-84

[29] Du L, Wei C, Cai S. Economic development and carbon dioxide emissions in China: Provincial panel data analysis. China Econ Rev 2012;23(2):371-84.

[30] Liddle B. Consumption-driven environmental impact and age-structure change in OECD countries: a cointegration-STIRPAT analysis. Demogr Res 2011;24:749-70.

[31] Cole MA, Neumayer E. Examining the impact of demographic factors on air pollution. Popul Environ 2004;26(1):5-21.

[32] Zhang C, Lin Y. Panel estimation for urbanization, energy consumption and $\mathrm{CO}_{2}$ emissions: a regional analysis in China. Energy Policy 2012;49:488-98.

[33] Zhu HM, You WH, Zeng Z. Urbanization and $\mathrm{CO}_{2}$ emissions: a semi-parametric panel data analysis. Econ Lett 2012;117(3):848-50.

[34] Wang S, Fang C, Guan X, Pan B, Ma H. Urbanisation, energy consumption, and carbon dioxide emissions in China: a panel data analysis of China's provinces. Appl Energy 2014;13:738-49.

[35] Wang P, Wu W, Zhu B, Wei Y. Examining the impact factors of energy-related $\mathrm{CO}_{2}$ emissions using the STIRPAT model in Guangdong Province. China. Appl Energy 2013:106:65-71.

[36] Menz T, Welsch H. Population aging and carbon emissions in OECD countries: accounting for life-cycle and cohort effects. Energy Econ 2012;34:842-9.

[37] Knight K, Rosa E, Schor J. Could working less reduce pressures on the environment? A cross-national panel analysis of OECD countries, 1970-2007. Global Environ Change 2013;23:691-700.

[38] York R. Demographic trends and energy consumption in European Union Nations, 1960-2025. Soc Sci Res 2007:36:855-72.

[39] Chen H, Jia B, Lau SSY. Sustainable urban form for Chinese compact cities: challenges of a rapid urbanized economy. Habitat Int 2008;32:28-40.

[40] Sharma SS. Determinants of carbon dioxide emissions: empirical evidence from 69 countries. Appl Energy 2011;88(1):376-82.

[41] Ponce de Leon Barido D, Marshall JD. Relationship between urbanization and $\mathrm{CO}_{2}$ emissions depends on income level and policy. Environ Sci Technol 2014:48(7):3632-9.

[42] Selden TM, Song D. Environmental quality and development: is there a Kuznets curve for air pollution? J Environ Econ Environ Manag 1994;27:147-62.

[43] Roca J, Padilla E, Farré M, et al. Economic growth and atmospheric pollution in Spain: discussing the environmental Kuznets curve hypothesis. Ecol Econ 2001;39(1):85-99.

[44] Fodha M, Zaghdoud O. Economic growth and pollutant emissions in Tunisia: an empirical analysis of the environmental Kuznets curve. Energy Policy 2010;38(2):1150-6.

[45] Martinez-Zarzoso I, Maruotti A. The impact of urbanization on $\mathrm{CO}_{2}$ emissions: evidence from developing countries. Ecol Econ 2011;70(7):1344-53.

[46] Shafiei S, Salim RA. Non-renewable and renewable energy consumption and $\mathrm{CO}_{2}$ emissions in OECD countries: a comparative analysis. Energy Policy 2014;66:547-56.

[47] Shahbaz M, Mutascu M, Azim P. Environmental Kuznets curve in Romania and the role of energy consumption. Renew Sustain Energy Rev 2013;18:165-73.

48] Shahbaz M, Khraief N, Uddin GS, Ozturk I. Environmental Kuznets curve in an open economy: a bounds testing and causality analysis for Tunisia. Renew Sustain Energy Rev 2014;34:325-36.

449] Park S, Lee Y. Regional model of EKC for air pollution: evidence from the Republic of Korea. Energy Policy 2011:39:5840-9.

[50] Ehrlich PR, Holdren JP. Impact of population growth. Science 1971;191(3977):1212-7. 
[51] Dietz T, Rosa EA. Rethinking the environmental impacts of population, affluence and technology. Hum Ecol Rev 1994;1:277-300.

[52] Grossman GM, Krueger AB. Economic growth and the environment. Q J Econ 1995; 110(2):353-77.

[53] Pesaran M. A simple panel unit root test in the presence of cross-section dependence. J Appl Econometrics 2007;22:265-312.

[54] Wooldridge JM. Econometric analysis of cross section and pane data. Cambridge, Massachusetts: The MIT Press; 2002.

[55] Greene WH. Econometric Analysis. Upper Saddle River, New Jersey: Prentice Hall; 2000.

[56] Pesaran MH. General diagnostic tests for cross section dependence in panels CESifo Working Paper; 2004.
[57] Beck N, Katz JN. What to do (and not to do) with time-series cross-section data. Am Polit Sci Rev 1995;89:634-47.

[58] Hoechle D. Robust standard errors for panel regressions with cross- sectional dependence. Stata J 2007;7:281-312.

[59] Zhang C, Xu J. Retesting the causality between energy consumption and GDP in China: Evidence from sectoral and regional analyses using dynamic panel data. Energ Econ 2012;34:1782-9.

[60] Managi S, Kaneko S. Environmental performance and returns to pollution abatement in China. Ecol Econ 2009;68(6):1643-51. 